IZA DP No. 5735

On the Origins of Gender Roles: Women and the Plough

Alberto Alesina

Paola Giuliano

Nathan Nunn

May 2011 


\title{
On the Origins of Gender Roles: Women and the Plough
}

\author{
Alberto Alesina \\ Harvard University, IGIER Bocconi, \\ NBER and CEPR \\ Paola Giuliano \\ University of California Los Angeles, \\ NBER, CEPR and IZA \\ Nathan Nunn \\ Harvard University, \\ NBER and BREAD
}
May 2011
IZA
P.O. Box 7240
53072 Bonn
Germany

Discussion Paper No. 5735

Phone: +49-228-3894-0

Fax: +49-228-3894-180

E-mail: iza@iza.org

\begin{abstract}
Any opinions expressed here are those of the author(s) and not those of IZA. Research published in this series may include views on policy, but the institute itself takes no institutional policy positions.

The Institute for the Study of Labor (IZA) in Bonn is a local and virtual international research center and a place of communication between science, politics and business. IZA is an independent nonprofit organization supported by Deutsche Post Foundation. The center is associated with the University of Bonn and offers a stimulating research environment through its international network, workshops and conferences, data service, project support, research visits and doctoral program. IZA engages in (i) original and internationally competitive research in all fields of labor economics, (ii) development of policy concepts, and (iii) dissemination of research results and concepts to the interested public.
\end{abstract}

IZA Discussion Papers often represent preliminary work and are circulated to encourage discussion. Citation of such a paper should account for its provisional character. A revised version may be available directly from the author. 


\section{ABSTRACT}

\section{On the Origins of Gender Roles: Women and the Plough}

This paper seeks to better understand the historical origins of current differences in norms and beliefs about the appropriate role of women in society. We test the hypothesis that traditional agricultural practices influenced the historical gender division of labor and the evolution and persistence of gender norms. We find that, consistent with existing hypotheses, the descendants of societies that traditionally practiced plough agriculture, today have lower rates of female participation in the workplace, in politics, and in entrepreneurial activities, as well as a greater prevalence of attitudes favoring gender inequality. We identify the causal impact of traditional plough use by exploiting variation in the historical geo-climatic suitability of the environment for growing crops that differentially benefited from the adoption of the plough. Our IV estimates, based on this variation, support the findings from OLS. To isolate the importance of cultural transmission as a mechanism, we examine female labor force participation of second-generation immigrants living within the US.

JEL Classification: D03, J16, N30

Keywords: $\quad$ culture, beliefs, values, gender roles

Corresponding author:

Paola Giuliano

Anderson School of Management

UCLA

110 Westwood Plaza

Entrepreneurs Hall C517

Los Angeles, CA 90095

USA

E-mail: paola.giuliano@anderson.ucla.edu

\footnotetext{
*We thank Samuel Bowles, David Clingingsmith, Esther Duflo, Raquel Fernandez, Nicole Fortin, Oded Galor, Pauline Grosjean, Judith Hellerstein, Edward Miguel, Rohini Pande, Louis Putterman, John Wallis, as well as seminar participants at the Bank of Italy, Brown University, Harvard University, Hong Kong University of Science and Technology, MIT, New York University, Sciences Po, UCLA Kaler Meeting, University of Oklahoma, Washington University St. Louis, World Bank, WAEHS, Stanford's SITE Conference, Coevolution of Behaviors and Institutions Conference, AEA Annual Meetings, Brooking Africa Growth Forum, NBER Political Economy Meeting, NBER Cohort Studies Meeting, and the IZA/Science Po Workshop on Trust, Civic Spirit and Economic Performance for valuable comments. We also thank Eva $\mathrm{Ng}$ for excellent research assistance. Giuliano gratefully acknowledges support from the UCLA Senate.
} 


\section{Introduction}

The gender division of labor varies significantly across societies. In some cultures women actively participate in employment outside of the home, while in others there is a clear specialization of tasks along gender lines: women tend to remain within the home and do not participate in activities outside of the domestic sphere. These differences are most clearly illustrated by the vast differences in female labor force participation (FLFP), which in 2000 ranged from $16.1 \%$ (Pakistan) to $90.5 \%$ (Burundi). ${ }^{1}$

Many determinants of these differences have been well-studied, including per capita income and the specialization of the economy in female-friendly industries (e.g., Goldin, 1995, Ross, 2008, Iversen and Rosenbluth, 2010). However, even controlling for these determinants there remain important time-invariant differences in gender roles. ${ }^{2}$ A number of studies have provided evidence that these persistent differences may be explained by differences in cultural beliefs about the appropriate role of women in society (Fortin, 2005, Fernandez, 2007, Fernandez and Fogli, 2009, Borck, 2011). However, this then raises the natural question of the origins of these differences in norms and beliefs.

This study tests the hypothesis, originally put forth by Ester Boserup (1970), that gender role differences have their origins in different forms of agriculture practiced traditionally. In particular, Boserup identifies important differences between shifting cultivation and plough cultivation. Shifting cultivation, which uses hand-held tools like the hoe and the digging stick, is labor intensive and women actively participate in farm-work. Plough cultivation, by contrast, is much more capital intensive, using the plough to prepare the soil. Unlike the hoe or digging stick, the plough requires significant upper body strength, grip strength, and burst of power, which are needed to either pull the plough or control the animal that pulls it. Because of these requirements, when plough agriculture is practiced, men have an advantage in farming relative to women (Murdock and Provost, 1973). ${ }^{3}$ Also reinforcing this gender-bias in ability is the fact that when the plough is used, there is less need for weeding, a task typically undertaken by women and children (Foster and Rosenzweig, 1996). In addition, child care, a task almost universally performed by women, is most compatible with activities that can be stopped and resumed easily and do not

${ }^{1}$ Data are from the World Bank's World Development Indicators.

${ }^{2}$ In Section 4, we provide evidence that these difference have persisted for centuries.

${ }^{3}$ See Pitt, Rosenzweig and Hassan (2010) for evidence from Bangladesh and the USA on the very different distributions of grip strength for men and women. 
put children in danger. These are characteristics that are satisfied for hoe agriculture, but not for plough agriculture, particularly since large animals are typically used to pull the plough.

The result, according to Boserup, is that societies that traditionally practiced plough agriculture - rather than shifting cultivation - developed a specialization of production along gender lines. Men tended to work outside of the home in the fields, while women specialized in activities within the home. ${ }^{4}$ This division of labor then generated norms about the appropriate role of women in society. Societies characterized by plough agriculture, and a resulting gender-based division of labor, developed the belief that the natural place for women is within the home. These cultural beliefs tend to persist even if the economy moves out of agriculture, affecting the participation of women on activities performed outside of the home, such as market employment, entrepreneurship, or participation in politics. ${ }^{5}$

To test Boserup's hypothesis, we combine pre-industrial ethnographic data, reporting whether societies traditionally used plough agriculture, with contemporary measures of individuals' views about gender roles, as well as measures of female participation in activities outside of the home. Our analysis examines variation across countries, ethnic groups, and individuals. Consistent with Boserup's hypothesis, we find a strong and robust negative relationship between historical plough-use and unequal gender roles today. Traditional plough-use is positively correlated with attitudes reflecting gender inequality and negatively correlated with female labor force participation, female firm ownership, and female participation in politics.

Although these findings support Boserup's hypothesis, they are also consistent with other interpretations. For example, we would observe the same relationships if societies with attitudes favoring gender inequality were more likely to adopt the plough historically and if these attitudes continue to persist today. To better understand whether past plough use did have a causal impact on subsequent cultural norms, we instrument historical plough-use using specific geo-climatic

\footnotetext{
4Prior to Boserup, anthropologists and ethnographers had recognized a relationship between traditional gender roles and the use of the hoe (e.g., Baumann, 1928). However, we focus our discussion here on Boserup's analysis since she was the first to argue for the importance of agricultural technology on the subsequent evolution of norms and values, and their importance for the development process.

5 Boserup (1970), in her analysis, most strongly argues for a relationship between traditional plough use and gender norms when she hypothesizes that the use of the veil may be associated with the use of the plough in agriculture. She writes that plough cultivation "shows a predominantly male labor force. The land is prepared for sowing by men using draught animals, and this...leaves little need for weeding the crop, which is usually the women's task... Because village women work less in agriculture, a considerable fraction of them are completely freed from farm work. Sometimes such women perform purely domestic duties, living in seclusion within their own homes only appearing in the street wearing a veil, a phenomenon associated with plough culture and seemingly unknown in regions of shifting cultivation where women do most of the agricultural toil." (pp. 13-14)
} 
conditions of a society's historical location which affected the relative benefits of adopting the plough. As Pryor (1985) shows, the benefit of the plough depends on the crop being cultivated. The plough is more beneficial for crops that require large tracts of land to be prepared in a short period of time (e.g., due to multiple-cropping), and can only be grown in soils that are not shallow, sloped, or rocky. ${ }^{6}$ These crops, which Pryor refers to as 'plough-positive', include teff, wheat, barley, rye and wet rice. These can be contrasted to 'plough-negative' crops, such as maize, sorghum, millet and various types of root and tree crops, which require less land to be prepared over a longer period of time, and/or can be cultivated on thin, sloped or rocky soils, where using the plough is difficult. Unlike plough-positive crops, plough-negative crops benefit much less from the adoption of the plough.

Using data from the FAO, we identify the geo-climatic suitability of finely defined locations for growing plough-positive cereals (wheat, barley and rye) and plough-negative cereals (sorghum and millet). We then use the relative differences in ethnic groups' geo-climatic conditions for growing plough-positive and plough-negative cereals as instruments for historical plough use. We find that the IV estimates provide results consistent with the OLS estimates. Traditional plough use is associated with attitudes of gender inequality, as well as less female labor force participation, female firm-ownership, and female participation in politics.

Our analysis then considers potential underlying mechanisms. It is possible that the long-term effect of the plough reflects persistent cultural beliefs. However, it is also possible that part of the long-term impact arises because historical plough-use promoted the development of institutions, policies and markets that are less conducive to the participation of women in activities outside of the home. ${ }^{7}$ To distinguish these two channels we exploit the fact that cultural norms and beliefs - unlike institutions, policies and markets - are internal to the individual. Therefore, when individuals move, their beliefs and values move with them, but their external environment remains behind. Exploiting this fact, we examine variation in cultural heritage among second-generation immigrants living in the US. All individuals born and raised in the US have been exposed to the same institutions and markets. In effect, the analysis holds external factors constant, while

\footnotetext{
${ }^{6}$ For a recent study documenting the link between soil type and plough-use in modern India see Carranza (2010). In particular, she shows that in contemporary India plough technology is more likely to be adopted with deep loamy soils rather than shallow clay soils. She also shows that plough use is associated with less participation of women in agriculture.

7See the recent studies by Alesina, Algan, Cahuc and Giuliano (2010), Guiso, Sapienza and Zingales (2008b) and Tabellini (2008) that investigate feedback effects between culture and institutions.
} 
examining variation in individuals' internal beliefs and values. We find that women from cultures that historically used the plough have lower rates of labor force participation in the US. This provides evidence that part of the importance of the plough arises through its impact on internal beliefs and values.

Our focus on a historical determinant of gender roles is not meant to imply that other factors, particularly factors that can change significantly over time, are unimportant. A number of existing studies have examined other important determinants, including economic development, medical progress, and the production structure of the economy (e.g., Iversen and Rosenbluth, 2010, Goldin, 2006, Ross, 2008, and Albanesi and Olivetti, 2007, 2009). As we show in section 4, even accounting for these important factors, there remains a strong persistent impact of the plough on gender norms today.

Our analysis complements a number of descriptive studies from history, anthropology and sociology that also examine the long-term impacts of traditional plough use on gender norms (Goody, 1976, Whyte, 1978 and Braudel, 1998). A particularly interesting example is Fernand Braudel's (1998) description of how gender relations, culture, and society were impacted by the adoption of the plough in Mesopotamia between 4,000 and 6,000 BC. He writes: "Until now, women had been in charge of the fields and gardens where cereals were grown: everything had depended on their tilling the soil and tending the crop. Men had been first hunters, then herdsmen. But now men took over the plough, which they alone were allowed to use. At a stroke, it might seem that the society would move from being matriarchal to patriarchal: that there would be a shift away from the reign of the all-powerful mother goddesses... and towards the male gods and priests who were predominant in Sumer and Babylon... and was accompanied with a move towards male domination of society and its beliefs" (p. 71).

Our results also add to a recent line of research that has emphasized the relevance of cultural norms and beliefs as important factors underlying the persistent differences in gender roles across societies (Alesina and Giuliano, 2010, Fernandez, 2007, Fernandez and Fogli, 2009, and Fortin, 2005, 2009). Although the link between gender norms and female labor force participation is wellestablished, little is known about the origin of these cultural differences. Our findings suggest that an important determinant of these differences can be found in traditional farming practices. More generally, our findings provide additional evidence showing that historical factors can shape the evolution and persistence of norms and beliefs. Thus, they contribute to an emerging literature 
that examines the historical determinants of various cultural characteristics today (e.g., Guiso, Sapienza and Zingales, 2008a, Grosjean, 2010a,b, Becker, Boeckh, Hainz and Woessman, 2010, Nunn and Wantchekon, 2011).

In the next section, we begin our analysis by first documenting that in societies that traditionally used plough agriculture women did in fact participate less in farm-work and other activities outside of the domestic sphere. In section 3, we then explain the procedure used to link the historical use of the plough, which is measured at the ethnicity level, to contemporary data on gender norms or female labor force participation, measured either at the country or individual level. Sections 4 and 5 report OLS and IV estimates of the relationship between traditional plough use and gender outcomes today, examining variation across individuals and countries. In section 6, we then turn to mechanisms, using second-generation US immigrants to test for persistent impacts of the plough through cultural transmission. Section 7 offers concluding thoughts.

\section{The historical impacts of traditional plough use}

We begin our analysis by first confirming that societies that traditionally used plough agriculture had lower female participation in agricultural activities. We also check whether plough use was associated with differences in other activities within and outside of the domestic sphere.

Our analysis relies on information on pre-industrial plough use taken from the Ethnographic Atlas, a world wide ethnicity-level database constructed by George Peter Murdock that contains ethnographic information for 1,267 ethnic groups around the world. Information for societies in the sample have been coded for the earliest period for which satisfactory ethnographic data are available or can be reconstructed. The earliest observation dates are for groups in the Old World where early written evidence is available. For the parts of the world without a written history the information is from the earliest observers of these cultures. For some cultures the first recorded information is from the early 2oth century. However, even for these observations, the data should capture, to the maximum extent possible, the characteristics of the ethnic group prior to European contact. For all groups in the dataset, the variables are taken from the societies prior to industrialization.

The database contains a measure of the historical use of plough agriculture. Groups are classified into one of three mutually exclusive categories: (i) the plough was absent, (ii) the plough existed at the time the group was observed but it was not aboriginal, and (iii) the plough 
was aboriginal and found in the society prior to contact. There are data on plough use for 1,158 of the 1,267 societies in the database. There is no evidence of groups switching from one form of agriculture to another and then back again. In other words, the use of the plough, once adopted, remains stable over time. Using the categorization, we construct an indicator variable for plough use which equals one if the plough was present (whether aboriginal or not) and zero otherwise.

It is possible that the plough has a larger impact on gender norms if it was adopted early. However, because of data limitation, we are unable to test for this. From the database we only know the rough date of adoption if it occurred after European contact. For other plough users we do not have any information on the timing of adoption. Given this, our estimates should be interpreted as the average effect of having adopted the plough among all ethnic groups that did so prior to industrialization. There may be heterogeneity within the group of adopters (e.g. based on date of adoption), but we are only able to estimate an average effect.

We measure traditional female participation in agriculture using information on the gender division of labor in agriculture reported in the Ethnographic Atlas. Ethnicities are grouped into one of the following five categories measuring gendered participation in agriculture: (1) males only, (2) males appreciably more, (3) equal participation, (4) female appreciably more, and (5) females only. ${ }^{8}$ Using this information, we construct a variable that takes on integer values ranging from 1 to 5 and is increasing in female specialization in agriculture. 9

When examining the relationship between the gender division of labor in agriculture and plough use, we are careful to control for a number of characteristics of ethnic groups which may be correlated with plough use and gender roles. We control for the presence of large domesticated animals, a measure of economic development, and a measure of political complexity. All measures are from the Ethnographic Atlas. ${ }^{10}$ The presence of domesticated animals is measured with an indicator variable that equals one if domesticated bovine or equine animals were present. Economic development is measured using the density of ethnic groups' settlements. Ethnicities are grouped into the following categories: (1) nomadic or fully migratory, (2) semi-nomadic, (3) semi-sedentary, (4) compact but not permanent settlements, neighborhoods of dispersed family

\footnotetext{
${ }^{8}$ The original classification in the Ethnographic Atlas distinguishes between "differentiated but equal participation" and "equal participation". Since this distinction is not relevant for our purposes, we combine the two categories into a single category of equal participation.

${ }^{9}$ For 232 ethnic groups agriculture was not practiced and therefore there is no measure of female participation in agriculture. For an additional 315 ethnic groups information for the variable is missing. These ethnic groups (547 in total) are omitted from the analysis.

${ }^{10}$ Full details are provided in the paper's appendix.
} 
homesteads, (5) separate hamlets, (6) forming a single community, (7) compact and relatively permanent settlements and (8) complex settlements. With this information, we construct a variable that takes on integer values, ranging from 1 to 8 , and is increasing in settlement density. Political complexity is measured by the number of levels of jurisdictional hierarchies in the society.

We also control for two measures of the geographic conditions of ethnic groups. For each ethnicity we know the geographic coordinates of the centroid of the group. Using this information, we calculate the fraction of land within a 200 kilometer radius of the centroid that is defined as suitable for the cultivation of crops. The crop suitability data are from the FAO's Global Agro-Ecological Zones (GAEZ) 2002 database (Fischer, van Nelthuizen, Shah and Nachtergaele, 2002), which reports suitability measures for 5 arc minute by 5 arc minute (approximately $56 \mathrm{~km}$ by $56 \mathrm{~km}$ ) grid-cells globally. The suitability of the environment for agriculture is potentially correlated with the use of the plough and may independently affect the gender division of labor. We also use the same procedure to control for the proportion of land within the 200 kilometer radius that is defined as being tropical or subtropical.

OLS estimates examining the impact of the historical plough use on past female participation in agriculture are reported in column 1 of Table 1 . The specification includes the five controls variables. The estimates identify a negative relationship between plough use and participation of women in agriculture. The use of the plough is associated with a reduction in the female participation in agriculture variable of 0.86 , which is large given that the standard deviation of the variable is 1.0.

A natural question that arises is the exact nature of this decline in female participation in agriculture; specifically, whether the decline is in all agricultural tasks or is it focused on only a few. Unfortunately, the Ethnographic Atlas does not provide similar information for specific tasks within agriculture. We therefore complement our analysis by using Murdock and White's (1969) Standard Cross-Cultural Sample (SCCS) which does contain this information. The SCCS contains ethnographic information on 186 societies, intentionally chosen to be representative of the full sample and for each ethnicity to be historically and culturally independent from the other ethnic groups in the sample. The database was constructed by first grouping the 1267 societies from the Ethnographic Atlas into 186 clusters of closely related cultures. A particularly well-documented and representative ethnic group was then chosen for each cluster and these constitute the observations in the SCCS. 
Table 1: Historical plough use and female participation in agriculture and other activities.

\begin{tabular}{|c|c|c|c|c|c|c|c|}
\hline & \multicolumn{7}{|c|}{ Panel A. Dependent variables: Female participation in the following (agriculture-related) tasks: } \\
\hline & Participation & in agriculture & Land clearance & $\begin{array}{c}\text { Soil } \\
\text { preparation }\end{array}$ & Planting & Crop tending & Harvesting \\
\hline & $(1)$ & $(2)$ & $(3)$ & $(4)$ & $(5)$ & $(6)$ & $(7)$ \\
\hline \multirow{2}{*}{ Historical plough use } & $-0.861 * * *$ & $-1.133^{* * *}$ & $-0.414^{* *}$ & $-1.164 * * *$ & $-1.244 * * *$ & $-1.033^{* * *}$ & $-0.770 * *$ \\
\hline & $(0.217)$ & $(0.272)$ & $(0.200)$ & $(0.355)$ & $(0.341)$ & $(0.367)$ & $(0.308)$ \\
\hline Ethnographic controls & yes & yes & yes & yes & yes & yes & yes \\
\hline Observations & 660 & 124 & 129 & 124 & 131 & 122 & 131 \\
\hline \multirow[t]{4}{*}{ R-squared } & 0.14 & 0.22 & 0.15 & 0.13 & 0.13 & 0.19 & 0.19 \\
\hline & \multicolumn{7}{|c|}{ Panel B. Dependent variables: Female participation in the following (additional) tasks: } \\
\hline & $\begin{array}{c}\text { Caring for } \\
\text { small animals }\end{array}$ & $\begin{array}{c}\text { Caring for } \\
\text { large animals }\end{array}$ & Milking & Cooking & Fuel gathering & Water fetching & $\begin{array}{l}\text { Burden } \\
\text { carrying }\end{array}$ \\
\hline & $(8)$ & (9) & $(10)$ & $(11)$ & $(12)$ & $(13)$ & $(14)$ \\
\hline \multirow[t]{2}{*}{ Historical plough use } & 0.296 & 0.173 & 0.318 & -0.006 & $-0.813^{*}$ & -0.166 & $-1.138^{* * *}$ \\
\hline & (0.574) & $(0.285)$ & $(0.736)$ & (0.128) & $(0.420)$ & $(0.246)$ & $(0.374)$ \\
\hline Ethnographic controls & yes & yes & yes & yes & yes & yes & yes \\
\hline Observations & 88 & 95 & 48 & 173 & 159 & 154 & 135 \\
\hline R-squared & 0.04 & 0.05 & 0.09 & 0.04 & 0.05 & 0.05 & 0.16 \\
\hline
\end{tabular}

Using the SCCS data, we first replicate the regression reported in column 1 that uses the Ethnographic Atlas data. As shown in column 2, we find similar results. Plough use is associated with a decline in female participation in agriculture of 1.13 , which is equal to a one standard deviation change in the dependent variable. In columns $3-7$, we estimate the association between plough use and female participation in the following agricultural tasks: land clearance, soil preparation, planting, crop tending and harvesting. The estimates show that plough use is associated with less female participation in all agricultural tasks, with the largest declines in soil preparation, planting and crop tending.

In columns 8-14, reported in panel B of Table 1 , we consider the relationship between plough use and female participation in non-agricultural activities: care of small and large animals, milking, cooking, fuel gathering, water fetching and burden carrying. ${ }^{11}$ We find that the plough is associated with less female participation in fuel gathering, water fetching, and burden carrying (although the coefficient for water fetching is small and not statistically different from zero). We do not find evidence that the plough is associated with a statistically significant increase in the

\footnotetext{
${ }^{11}$ If an activity is not present in a society, then the dependent variable is coded as missing. This accounts for the varying number of missing observations in each regression.
} 
other activities: caring for large or small animals, milking or cooking. For these activities, with the exception of cooking, the estimated coefficients are positive, but insignificant.

Overall, the ethnographic evidence confirms that women participated less in farm activities in societies that historically practiced plough agriculture. This is consistent with the analysis of Boserup (1970), as well as the observations of anthropologists like Baumann (1928) and Whyte (1978). There is some evidence that the reduced participation coincided with an increase in some activities like milking. However, the increases are not statistically significant.

\section{Linking the past to the present: Data and methodology}

We next turn to an examination of the long-term impact of historical plough use. To do this, we link historical plough-use, measured at the ethnicity level, with current outcomes of interest, measured at the location-level (either countries or districts within countries) today. This requires an estimate of the geographic distribution of ethnicities across the globe today. We construct this information using the 15th edition of the Ethnologue: Languages of the World (Gordon, 2005), a data source that maps the current geographic distribution of 7,612 different languages, each of which we manually matched to one of the 1,267 ethnic groups from the Ethnographic Atlas. The Ethnologue provides a shape file that divides the world's land into polygons, with each polygon indicating the location of a specific language. We also use the Landscan 2000 database, which reports estimates of the world's population for 30 arc-second by 30 arc-second (roughly $1 \mathrm{~km}$ by $1 \mathrm{~km}$ ) grid-cells globally. ${ }^{12}$ We combine the Ethnologue shape file with the Landscan raster file to obtain an estimate of the global distribution of language groups across the globe today. This information is used to link the historical ethnicity-level data to our current outcomes of interest, measured at the location-level.

We illustrate our procedure with the example of Ethiopia. Figure 1a shows a map of the land inhabited by different ethnic groups, i.e. groups speaking different languages. Each polygon represents the approximate borders of a group (from Ethnologue). One should not think of the borders as precisely defined boundaries, but rather as rough measures indicating the approximate locations of different language groups. The map also shows the Landscan estimate of the population of each cell within the country. A darker shade indicates greater population.

\footnotetext{
${ }^{12}$ The Landscan 2000 database was produced by Oakridge Laboratories in cooperation with the US Government and NASA.
} 
From the Ethnographic Atlas we know whether each ethnic group used the plough. We define $I_{e}^{\text {plough }}$ to be a variable equal to one if ethnic group $e$ used plough agriculture and zero otherwise. We first match each of the 7,612 Ethnologue language groups to one of the 1,267 Ethnographic Atlas ethnic groups for which we have traditional plough-use information. After the matching procedure, we know for each language group whether their ancestors engaged in plough agriculture. This information is shown in Figure $1 \mathrm{~b}$.

We then use information on the location of modern district and country boundaries to construct district-level and country-level averages of the historical plough measure. The procedure is shown visually for the district-level averages in Figures $2 a$ and $2 b$. Intuitively, the procedure creates a population-weighted average plough measure for all grid-cells within a district (or country). This provides an estimate of the fraction of the population currently living in a district (or country) with ancestors that traditionally engaged in plough agriculture.

To be more precise, let $N_{e, i, d, c}$ denote the number of individuals of ethnicity $e$ living in grid-cell $i$ located in district $d$ in country $c$. We then construct a population-weighted average of $I_{e}^{\text {plough }}$ for all ethnic groups living in a district $d$. The district-level measure of the fraction of the population with ancestors that traditionally used the plough, Plough ${ }_{d, c^{\prime}}$ is given by:

$$
\text { Plough }_{d, c}=\sum_{e} \sum_{i} \frac{N_{e, i, d, c}}{N_{d, c}} \cdot I_{e}^{\text {plough }}
$$

where $N_{d, c}$ is the total number of people living in district $d$ in country $c$. The same procedure is used to construct a country-level measure Plough ${ }_{c}$ as well, except that an average is taken over all grid-cells in country $c$.

Figure za shows the global distribution of languages based on the Ethnologue data, as well as historical plough use for each group. (The figure also shows uninhabited land in dark grey.) One shortcoming of the Ethnologue data is that information is missing for some parts of the world. This is due to uncertainty or a lack of information about the boundaries of language groups in that location. As it is apparent from the map, this primarily occurs in South America. We undertake three strategies to address this issue. The first is to ignore the missing languages and calculate country and district measures using the data that exist. This is the strategy that has been undertaken by other studies using the Ethnologue language data (e.g., Michalopoulos, 2008). Our second strategy is to assume that all inhabitants in the unclassified territories speak the national language of the country. The spatial distribution of historical plough use using this 


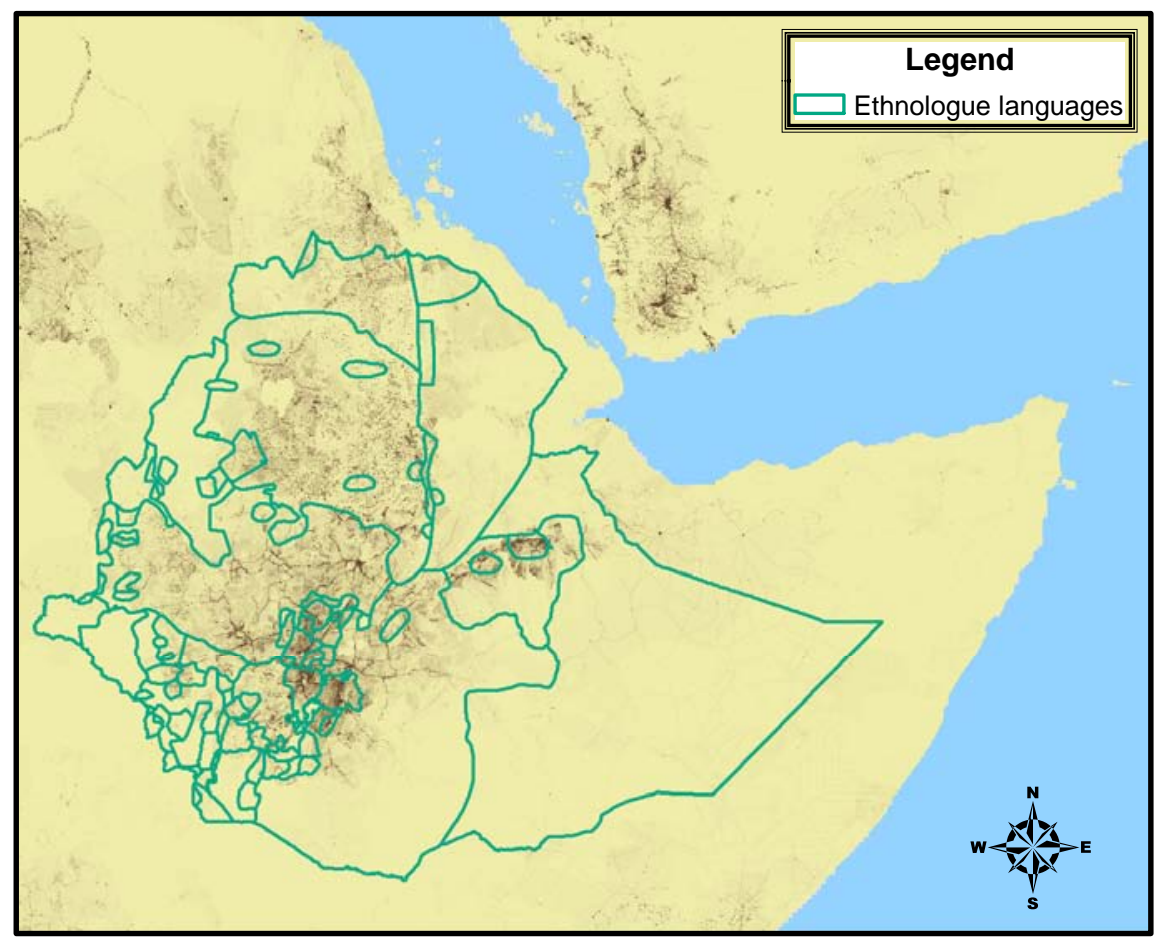

(a) Population density and language groups

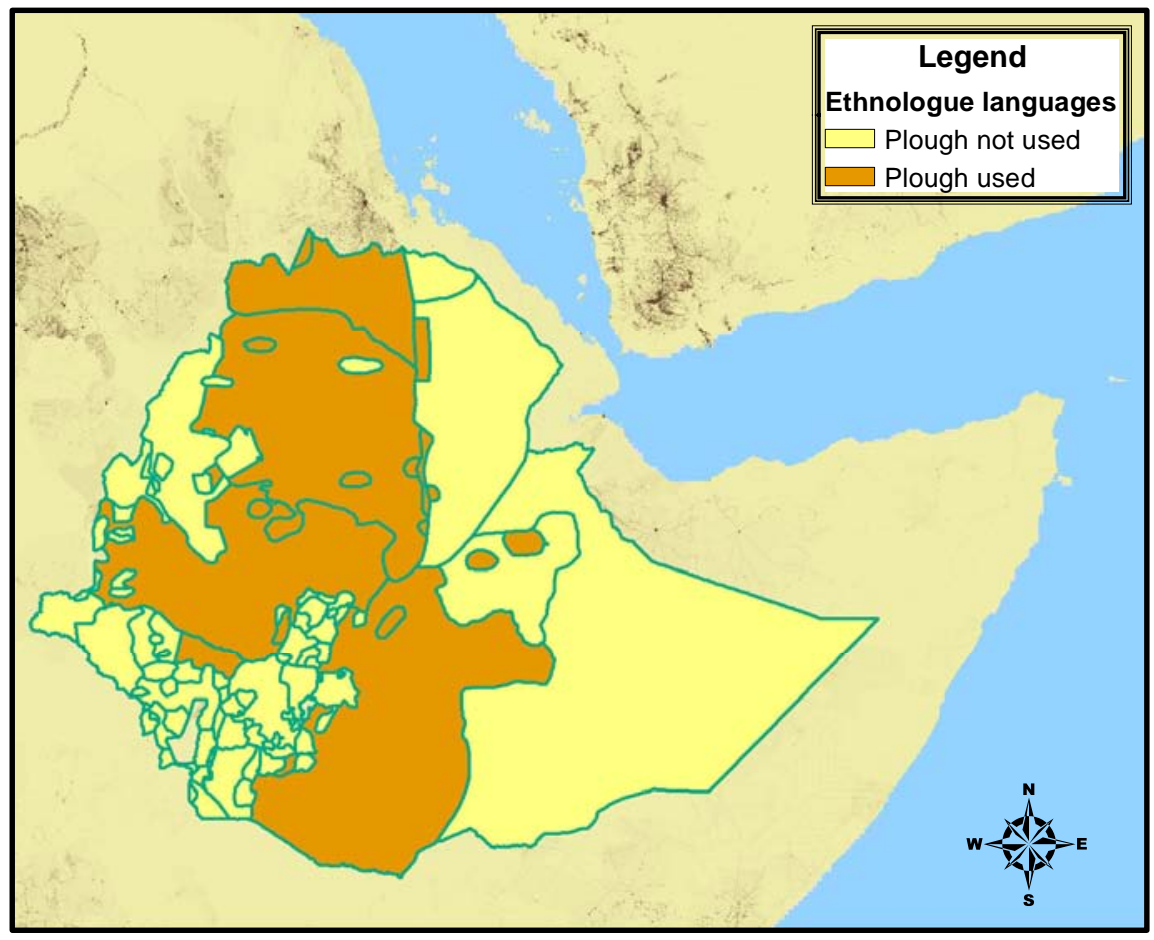

(b) Population density, language groups and their traditional plough use

Figure 1: Populations, language groups, and historical plough-use within Ethiopia. 


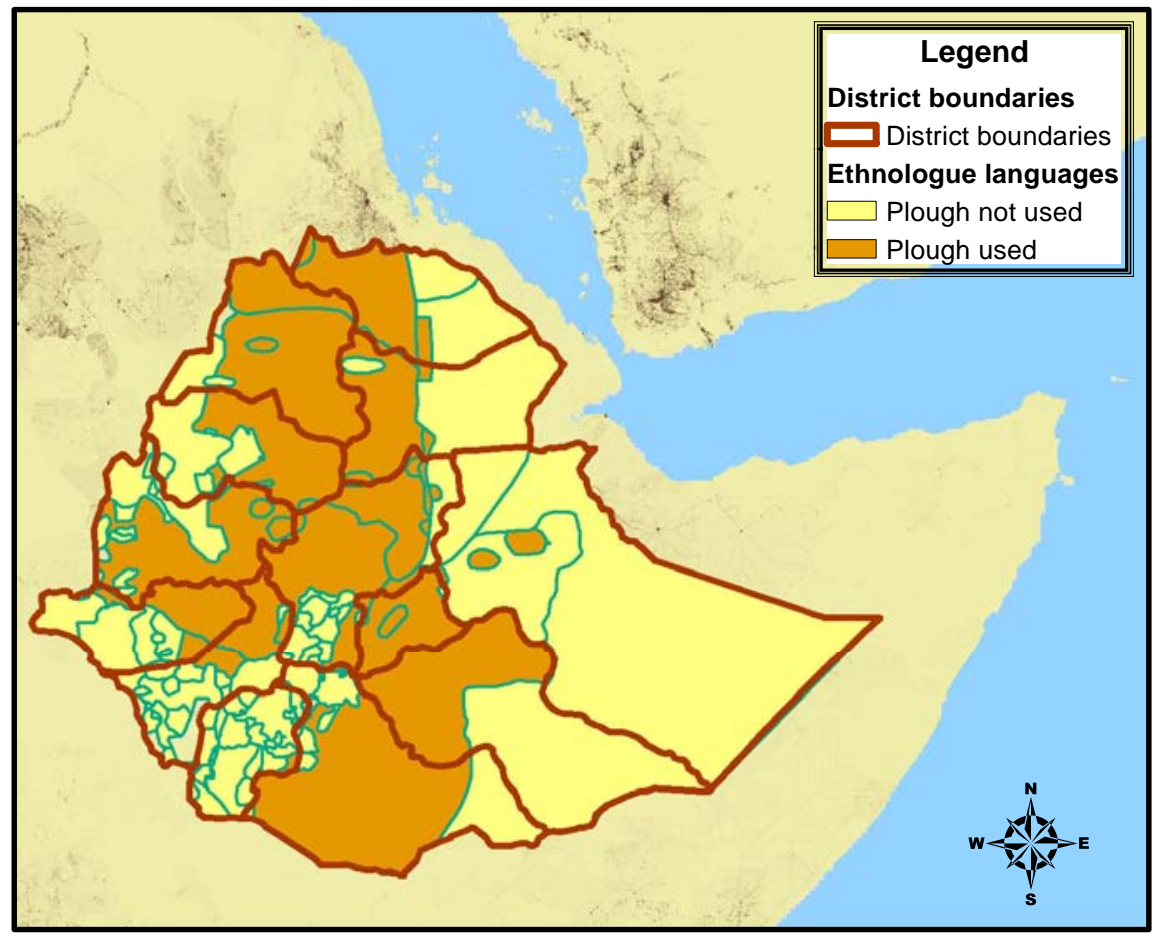

(a) Population density, language groups their traditional plough use, and districts today

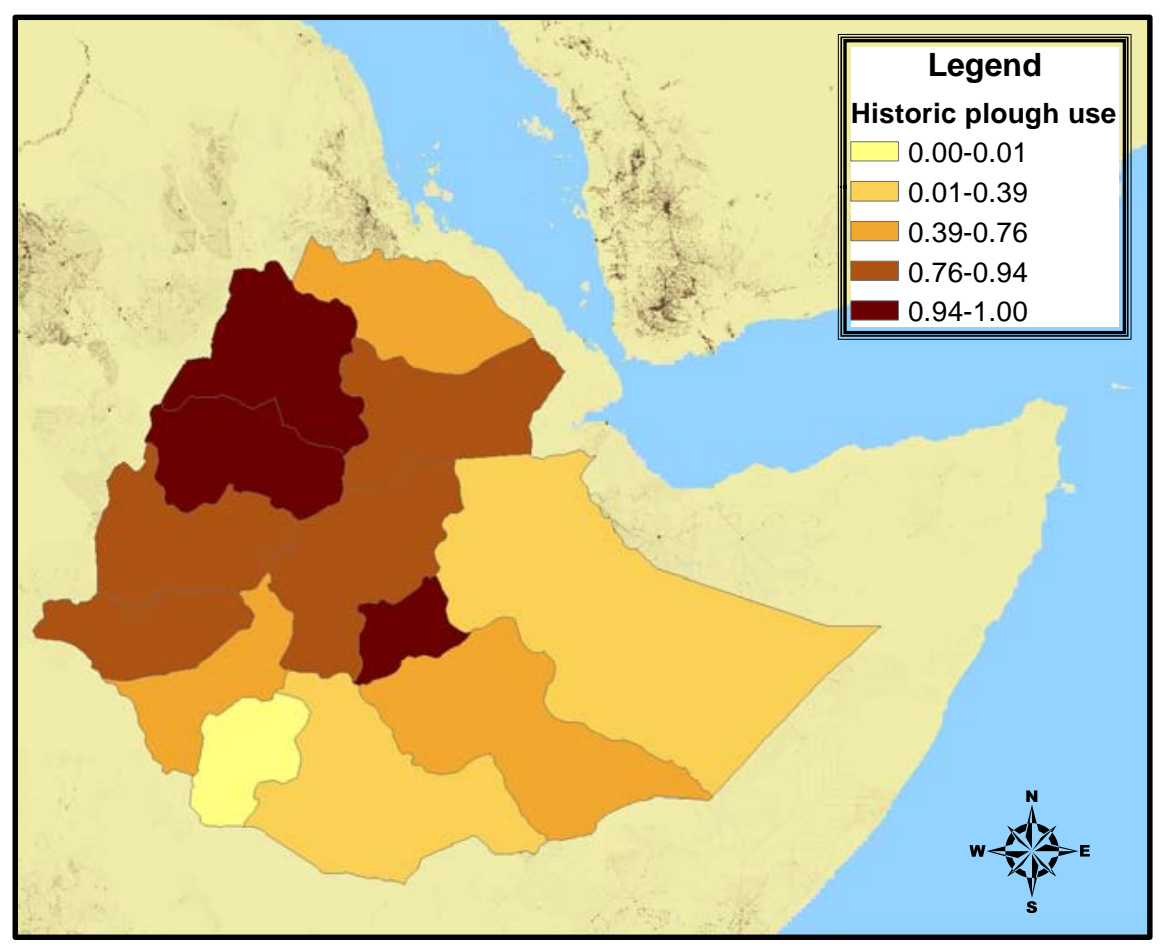

(b) District averages of plough use among inhabitants' ancestors

Figure 2: Traditional plough-use across districts within Ethiopia 


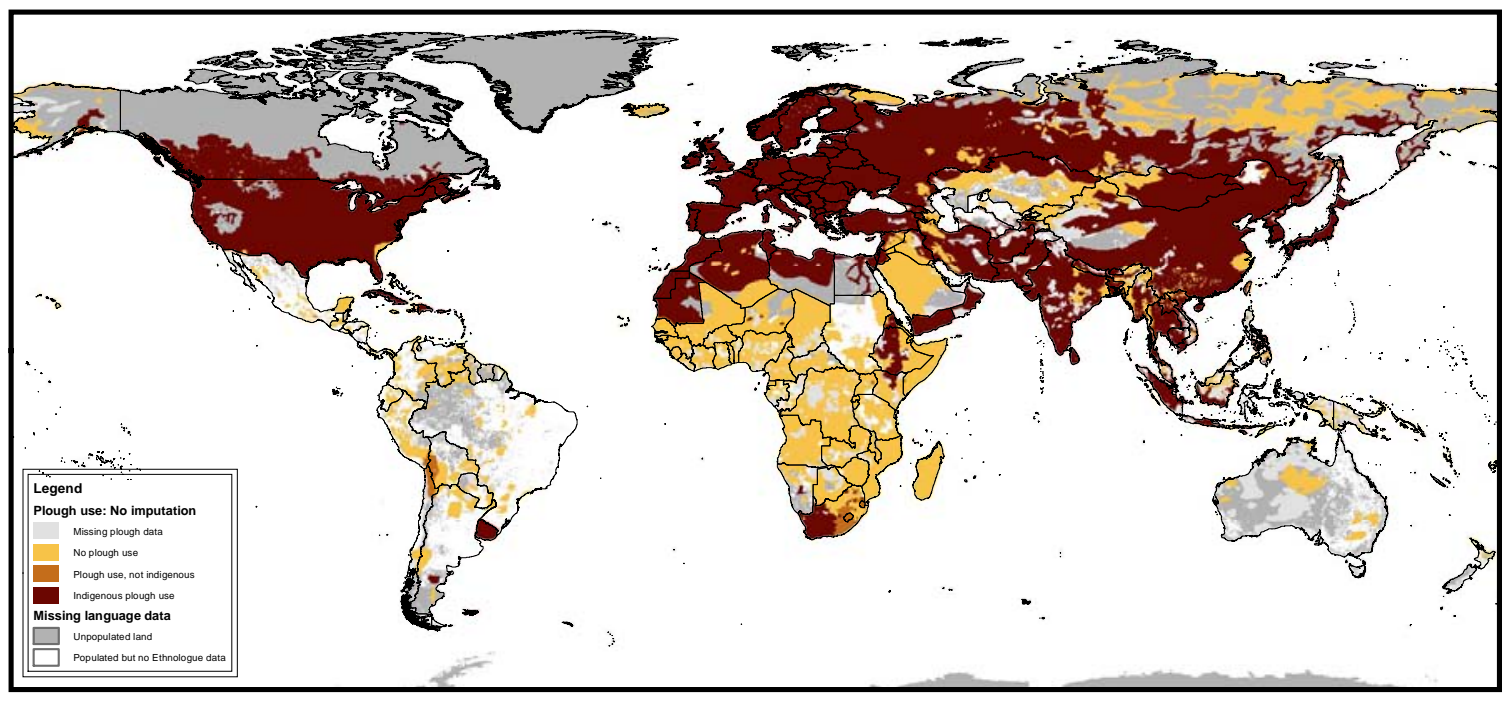

(a) Missing language information not imputed

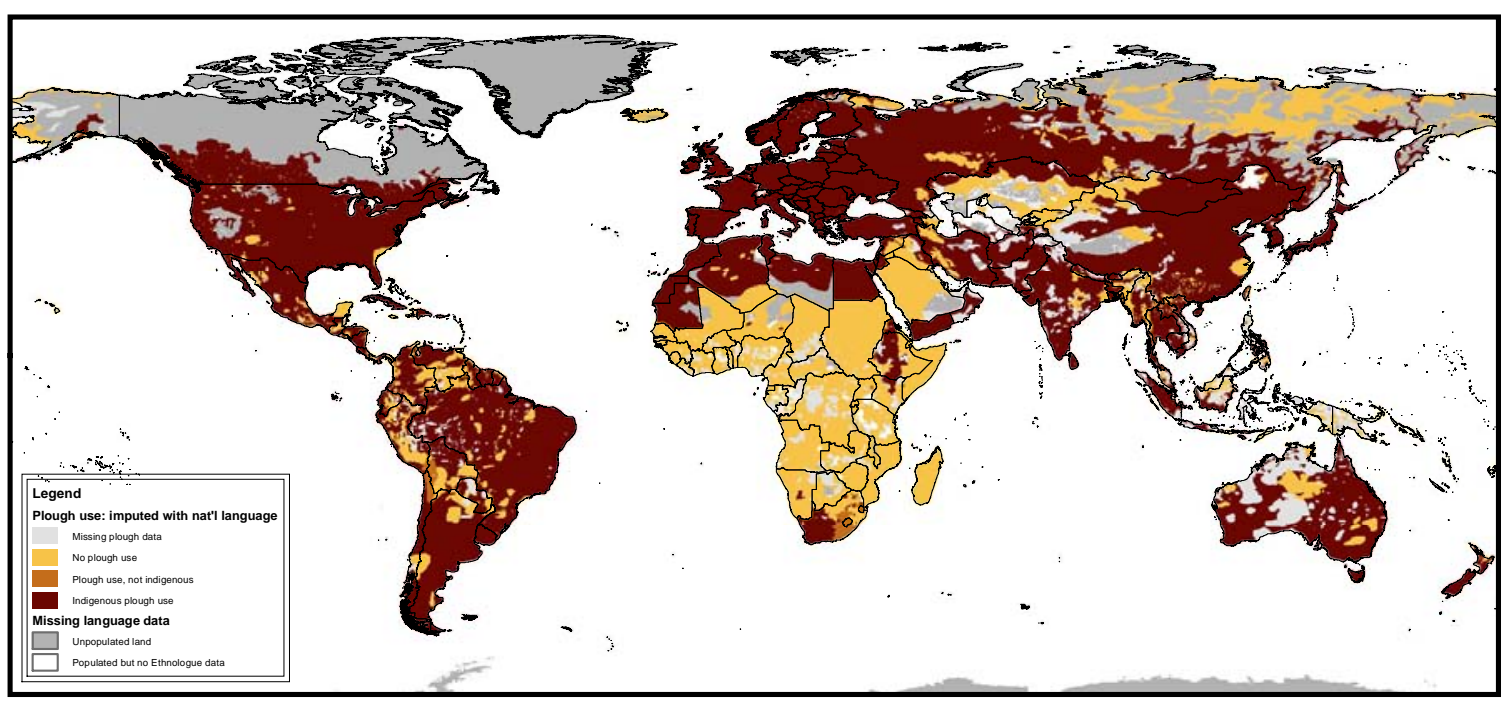

(b) Missing language information imputed using the country's official language

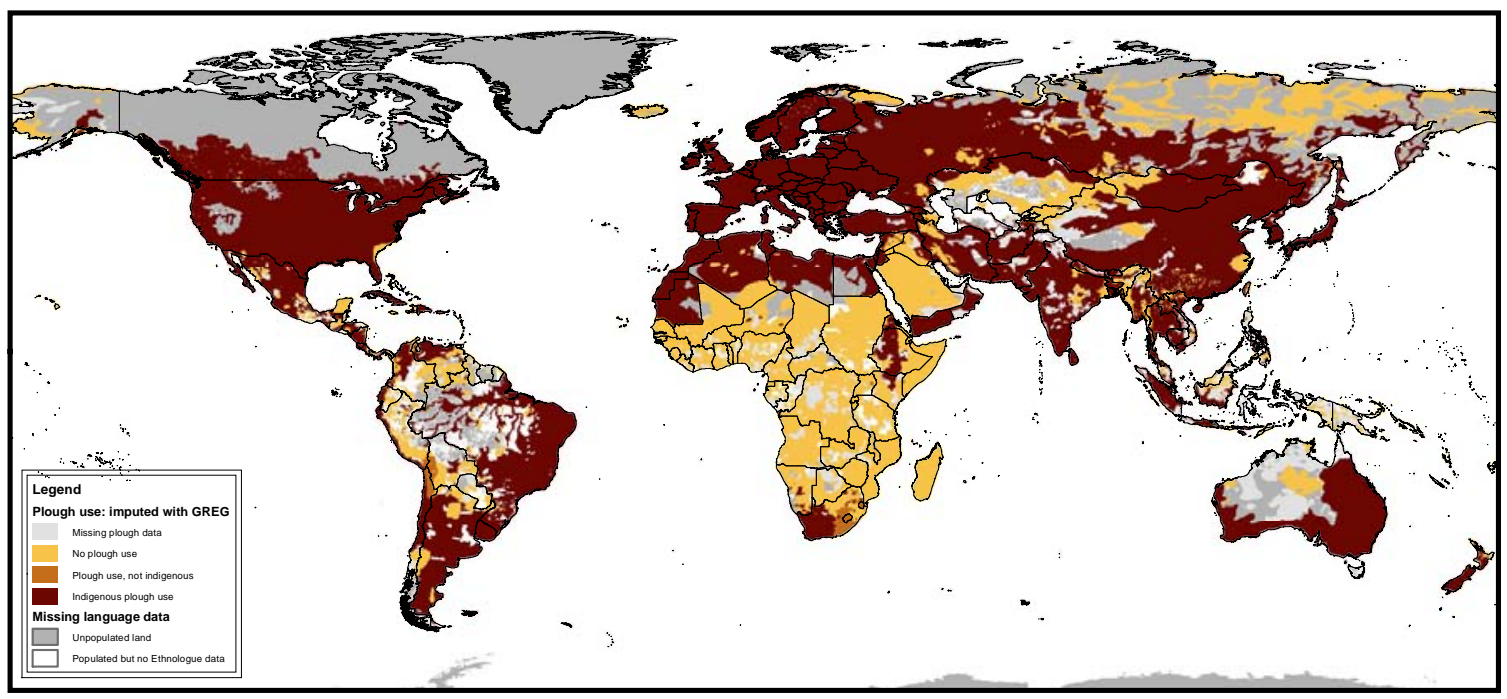

(c) Missing language information imputed using GREG ethnic groups

Figure 3: Historical plough use among the ethnic/language groups globally 
imputation procedure is reported in Figure $3 \mathrm{~b}$. Our third strategy is to impute the missing data using information on the spatial distribution of ethnic groups from the Geo-Referencing of Ethnic Groups (GREG) database (Weidmann, Rod and Cederman, 2010). Like the Ethnologue, the GREG database provides a shape file that divides the world's land into polygons, with each polygon indicating the location of a specific ethnicity. The shortcoming of the GREG database is that ethnic groups are much less finely identified relative to the Ethnologue database. The GREG database identifies 1,364 ethnic groups, while the Ethnologue identifies 7,612 language groups. ${ }^{13}$ The spatial distribution of historical plough use using this procedure is shown in Figure $3 c$.

In Figures $4 \mathrm{a}-4 \mathrm{c}$, we report population weighted country-level averages of historical plough use for each of the three strategies used to address the missing language data. In our analysis, we use the plough variable that was constructed without missing values imputed as our baseline measure. Our results are robust to the use of either variable that imputes the missing language data. This robustness is explained by the high correlation among the three plough measures. At the country-level, the correlation between: $(i)$ our baseline variable and the measure with missing languages imputed using the country's national language is o.89; (ii) our baseline measure and the measure imputed using ethnic groups from the GREG database is 0.91; and (iii) the two variables with imputed values is $0.99 .{ }^{14}$

\section{OLS estimates}

Having constructed country- and district-level measures of traditional plough use, we are able to examine the relationship between historical plough use and the role of women in societies today. We begin by examining variation at the country level.

\section{A. Country-level estimates}

We test Boserup's hypothesis by estimating the following equation:

$$
y_{c}=\alpha+\beta \text { Plough }_{c}+\mathbf{X}_{c}^{\mathbf{C}} \boldsymbol{\Gamma}+\mathbf{X}_{c}^{\mathbf{H}} \boldsymbol{\Pi}+\varepsilon_{c}
$$

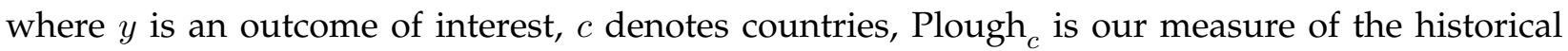
use of the plough among the ancestors of the citizens in country $c$, and $\mathbf{X}_{c}^{\mathbf{C}}$ and $\mathbf{X}_{c}^{\mathbf{H}}$ are vectors

\footnotetext{
${ }^{13}$ An alternative strategy is to rely only on the coarser GREG classification and map. Our results are robust to this procedure as well.

${ }^{14}$ Descriptive statistics for the three measures are reported in Appendix Table A1.
} 


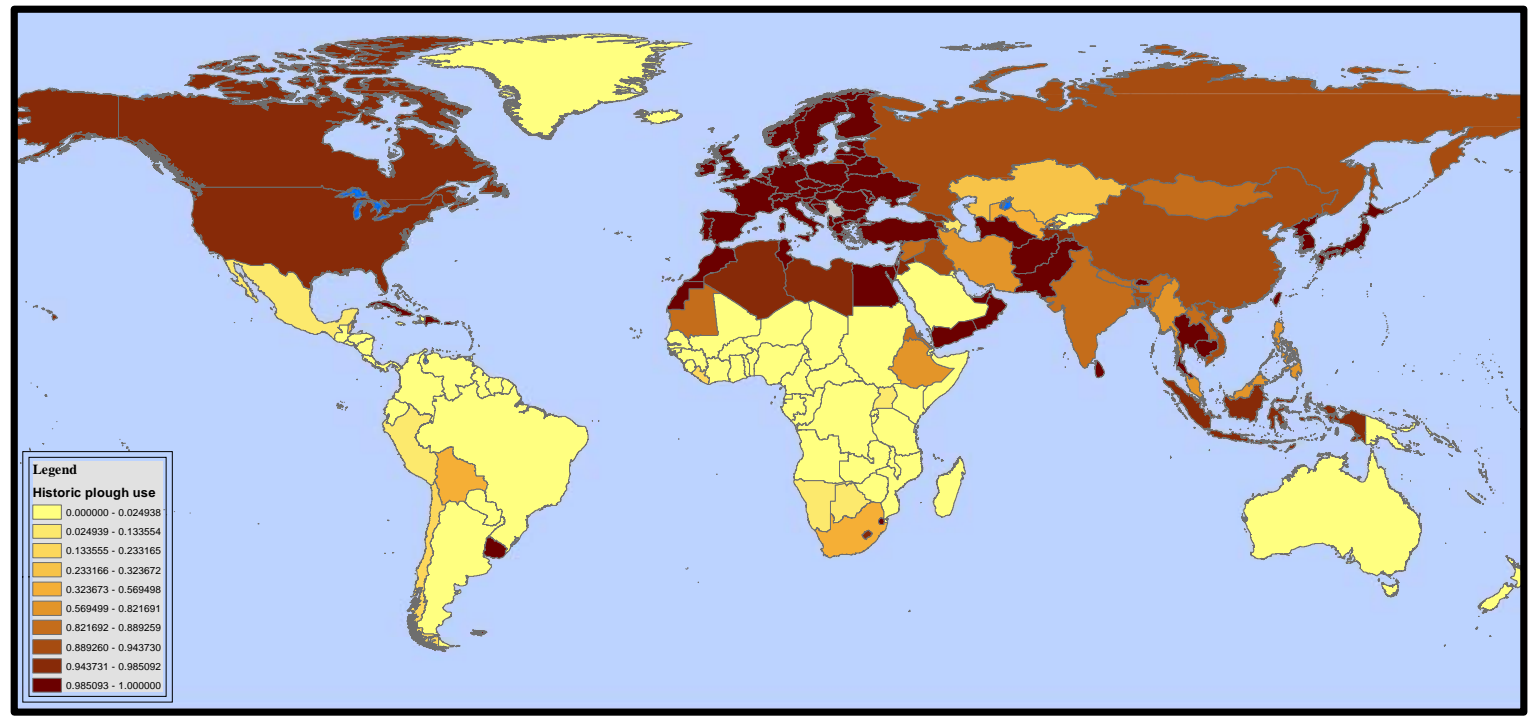

(a) Missing language information not imputed

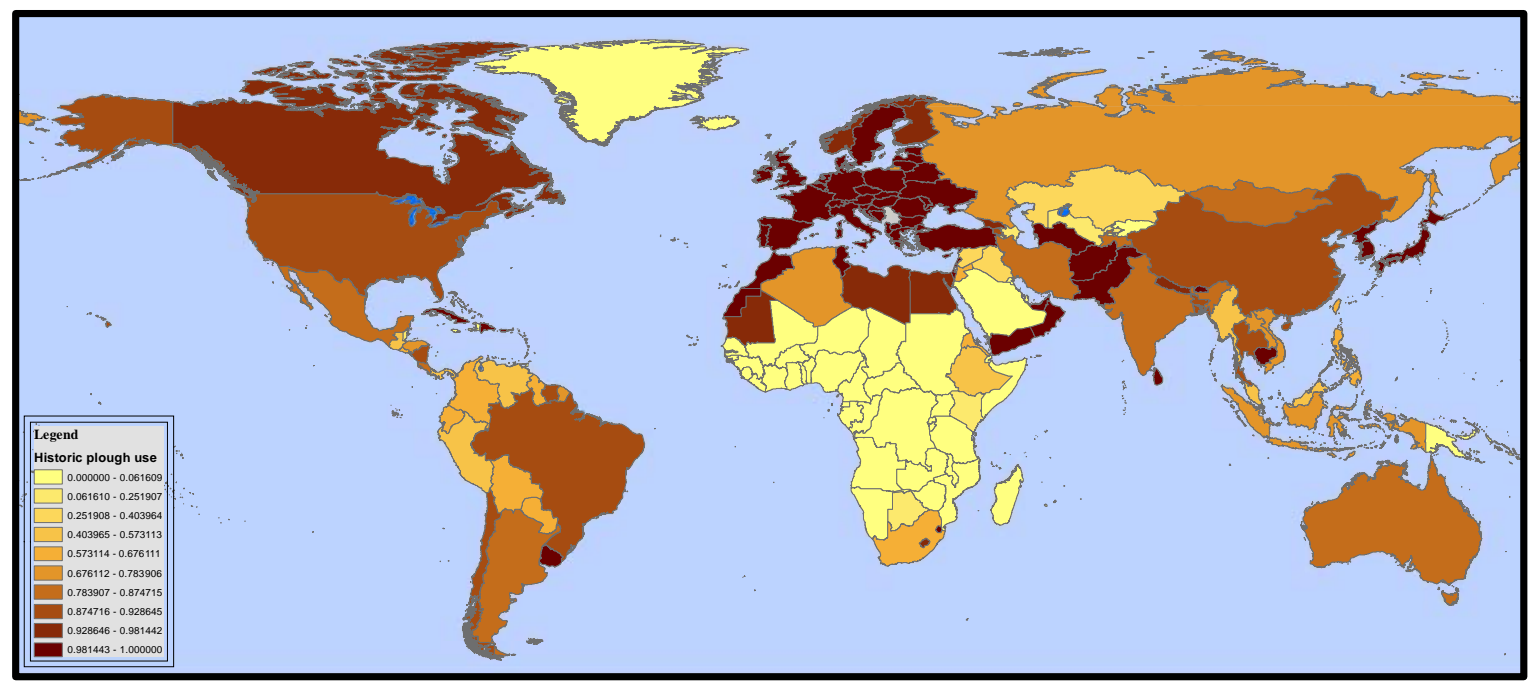

(b) Missing language information imputed using the country's official language

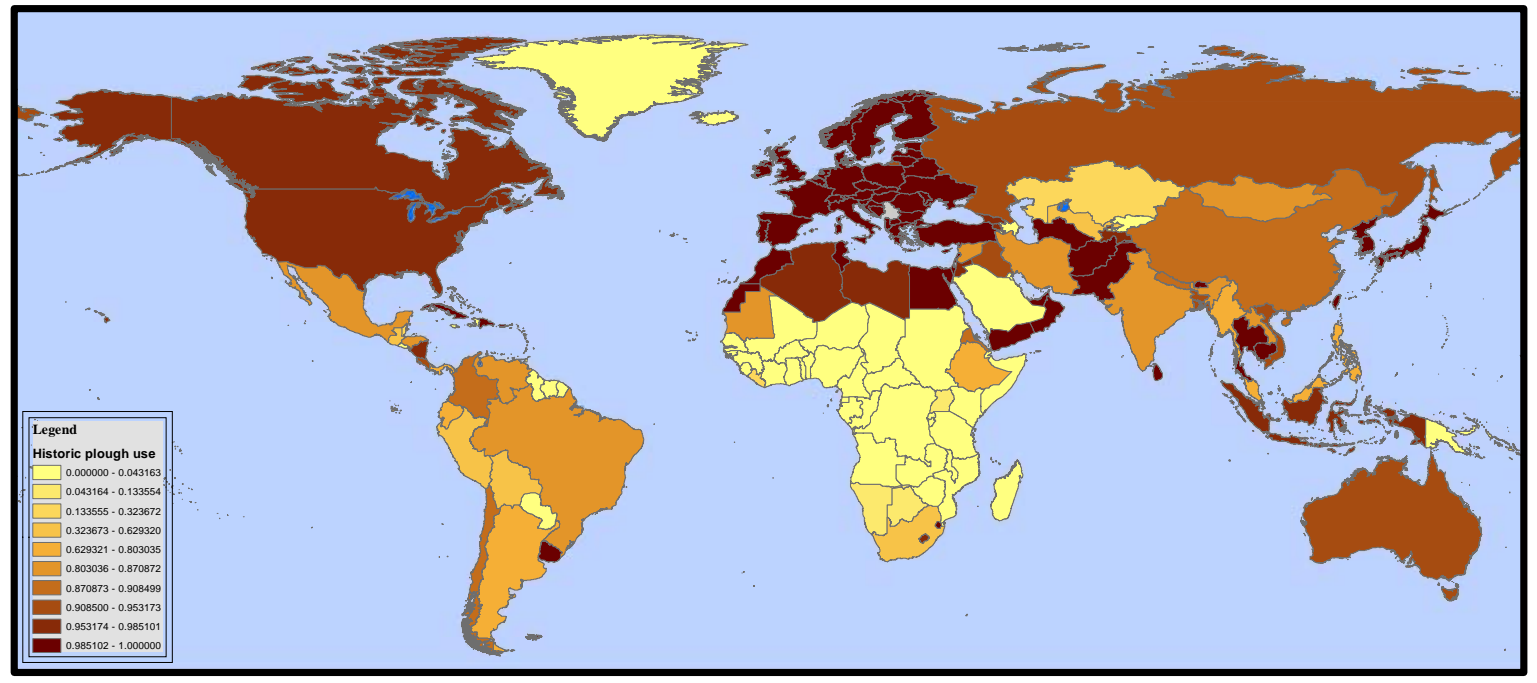

(c) Missing language information imputed using GREG ethnic groups

Figure 4: Average historical plough use among the ancestors of each country 
of current controls and historical ethnographic controls, all measured at the country level. $\mathbf{X}_{c}^{\mathrm{C}}$ includes the natural log of a country's real per capita GDP measured in 2000, as well as the variable squared. These controls are important given the well-established non-linear U-shaped relationship between economic development and female labor force participation (Goldin, 1995). We also include an indicator variable that equals one if the country was formerly communist, since these regimes implemented policies to eliminate gender differences in the economy. ${ }^{15}$ The historical ethnographic controls $\mathbf{X}_{c}^{\mathbf{H}}$ are based on the ethnographic characteristics used as controls in the ethnicity-level regressions: the presence of domesticated bovine or equine animals, economic development measured by the density of settlement, levels of political authority in the society, agricultural suitability, and the presence of a tropical climate. We construct country-level versions of these variables using the same procedure that is used to construct the historical plough use variable. Thus, the ethnographic controls capture the historical characteristics of a location's ancestors.

Table 2 reports country-level OLS estimates. In columns 1 and 2, the dependent variable is a country's female labor force participation rate (FLFP) in $2000 .{ }^{16}$ In columns $3-6$, we examine women's participation in more narrowly specified activities outside of the domestic sphere: entrepreneurship (measured by the share of firms with owners or managers that are female) and national politics (measured by the proportion of seats held by women in national parliament). ${ }^{17}$ The even numbered columns include controls for continent fixed effects, while the odd numbered columns do not. The estimates show that in countries with a tradition of plough use, women are less likely to participate in the labor market, are less likely to own or manage firms, and are less likely to participate in politics. ${ }^{18}$ All coefficients are negative and statistically significant.

The partial correlation plots for historical plough use are show in Figures $5 \mathrm{a}-5 \mathrm{c}$ (for columns

\footnotetext{
${ }^{15}$ Alesina and Fuchs-Schundeln (2007) show how the impact of a communist regime on individual beliefs can be long lasting.

${ }^{16} \mathrm{FLFP}$ is taken from the World Bank's World Development Indicators. The variable is measured as the percentage of women aged 15 to 64 that are in the labor force.

17The share of a country's firms with some female ownership is measured as the percentage of surveyed firms with a woman among the principal owners. The data are from the World Bank Enterprise Surveys. The proportion of seats in national parliament is measured as the percent of parliamentary seats, in a single or lower chamber, held by women. The variable, measured in 2000, is taken from the United Nations' Women's Indicators and Statistics Database.

${ }^{18}$ Because female participation in national politics may be affected by the type of government, we also control for each country's level of democracy in 2000 when this outcome is examined. Democracy is measured using the 'polityz' measure from the Polity IV database, which takes on integer values and ranges from -10 (high autocratic) to +10 (highly democratic). Many countries have introduced quotas to increase the participation of women in politics. We have checked the robustness of our results excluding countries with gender quotas. For the restricted sample of 86 countries, the estimated coefficient is -4.85 with a standard error of 2.68 .
} 
Table 2: Country level OLS estimates.

\begin{tabular}{|c|c|c|c|c|c|c|c|c|}
\hline & \multicolumn{8}{|c|}{ Dependent variable: } \\
\hline & \multicolumn{2}{|c|}{$\begin{array}{c}\text { Female labor force } \\
\text { participation }\end{array}$} & \multicolumn{2}{|c|}{$\begin{array}{c}\text { Share of firms with some } \\
\text { female ownership }\end{array}$} & \multicolumn{2}{|c|}{ Females in politics } & \multicolumn{2}{|c|}{ Average effect size (AES) } \\
\hline & $(1)$ & $(2)$ & (3) & $(4)$ & (5) & $(6)$ & $(7)$ & $(8)$ \\
\hline Historical plough use & $\begin{array}{c}-16.506 * * * \\
(3.547)\end{array}$ & $\begin{array}{c}-15.417^{* * *} \\
(3.561)\end{array}$ & $\begin{array}{c}-11.052 * * \\
(4.287)\end{array}$ & $\begin{array}{c}-11.540 * * \\
(5.152)\end{array}$ & $\begin{array}{c}-5.606 * * * \\
(2.128)\end{array}$ & $\begin{array}{l}-4.245^{*} \\
(2.218)\end{array}$ & $\begin{array}{c}-0.849 * * * \\
(0.140)\end{array}$ & $\begin{array}{c}-0.796 * * * \\
(0.137)\end{array}$ \\
\hline \multicolumn{9}{|l|}{ Historical controls: } \\
\hline Agricultural suitability & yes & yes & yes & yes & yes & yes & yes & yes \\
\hline Domesticated animals & yes & yes & yes & yes & yes & yes & yes & yes \\
\hline Tropics & yes & yes & yes & yes & yes & yes & yes & yes \\
\hline Political hierarchies & yes & yes & yes & yes & yes & yes & yes & yes \\
\hline Economic complexity & yes & yes & yes & yes & yes & yes & yes & yes \\
\hline \multicolumn{9}{|l|}{ Contemporary controls: } \\
\hline In income, In income ${ }^{2}$ & yes & yes & yes & yes & yes & yes & yes & yes \\
\hline Communism indicator & yes & yes & yes & yes & yes & yes & yes & yes \\
\hline Polity & no & no & no & no & yes & yes & no & no \\
\hline Continent fixed effects & no & yes & no & yes & no & yes & no & yes \\
\hline Observations & 159 & 159 & 105 & 105 & 125 & 125 & $135^{a}$ & $135^{a}$ \\
\hline R-squared & 0.41 & 0.43 & 0.15 & 0.21 & 0.28 & 0.32 & & \\
\hline
\end{tabular}

1, 3 and 5). From the figures it is clear that the coefficient for traditional plough use is not being influenced by a small number of countries. Further, the plots also show that the coefficient estimates are not only identified from broad differences across regions, but also from finer within-region variation. For example, we observe African countries in the Northwest corner (e.g., Rwanda, Madagascar) and in the Southeast corner (e.g., Eritrea, Mauritania, Ethiopia, etc). This is confirmed by the fact that the point estimates controlling for region fixed effects are essentially identical to the estimates without the fixed effects (comparing the odd numbered columns to the even numbered columns in Table 2).

Not only are the coefficient estimates statistically significant, but they are also economically meaningful. Based on the estimates from column 1, a one-standard-deviation increase in historical plough use (0.474) is associated with a reduction of female labor force participation (FLFP) of 7.82 percentage points $(16.506 \times 0.474)$, which is equal to $15.1 \%$ of the sample average for FLFP and $47 \%$ of its standard deviation. The impact on the share of firms with some female ownership (based on the column 3 estimates) is a reduction of 5.23 percentage points, which is $16 \%$ of the outcome's mean and $38 \%$ of its standard deviation. The reduction on the participation of women in politics (using the column 5 estimates) is 2.66 percentage points, which is $22 \%$ of the outcome's mean and $30 \%$ of its standard deviation. ${ }^{19}$

\footnotetext{
${ }^{19}$ See Appendix Table A1 for the means and standard deviations of the variables.
} 


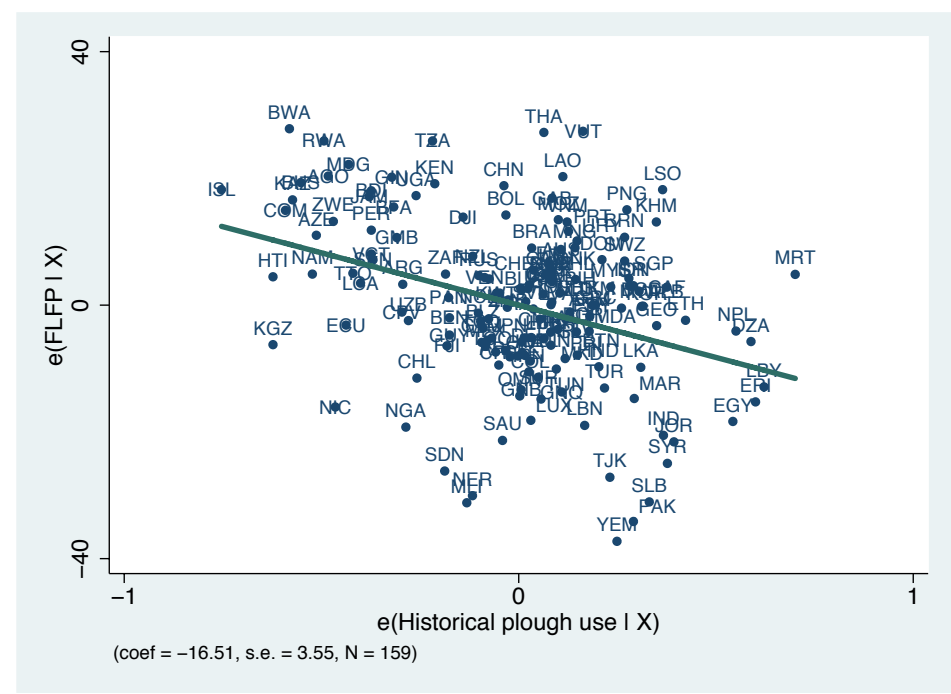

(a) Female labor force participation

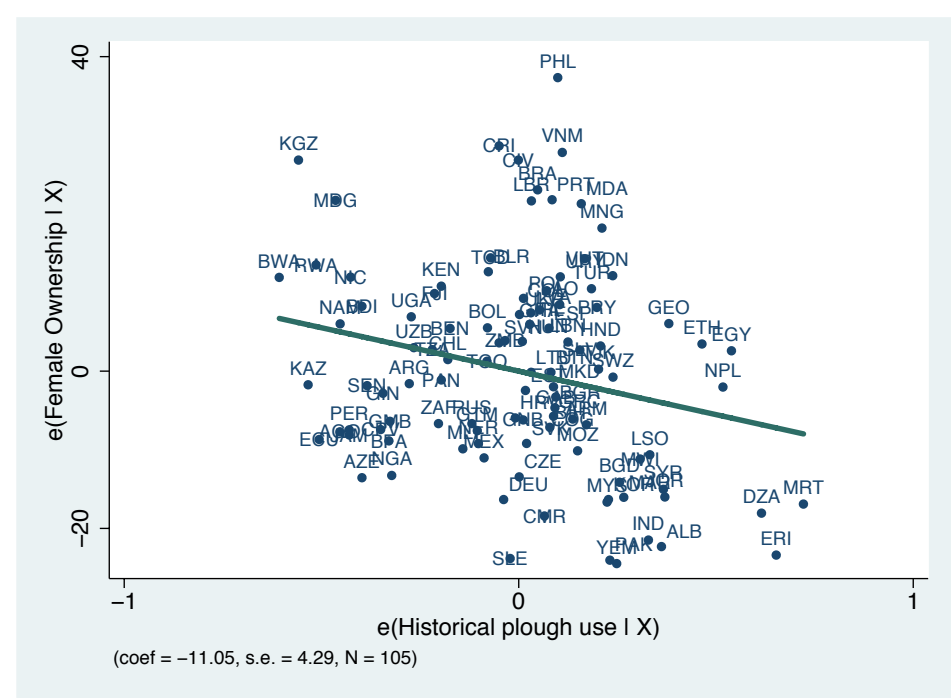

(b) Female ownership or managing of firms

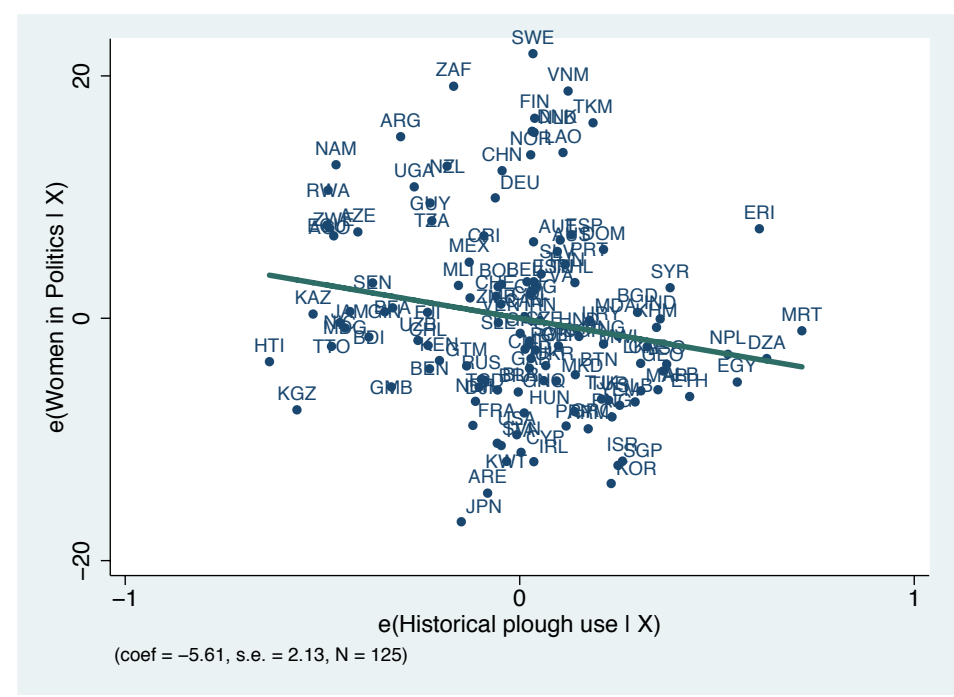

(c) Female participation in politics

Figure 5: Partial correlation plots for historical plough use, Plough ${ }_{c}$. 
Columns 7 and 8 report the estimated average effect size (AES) for the three dependent variables examined in columns 1-6. We computed the AES following Kling, Liebman, Katz and Sanbonmatsu (2004). Let $\beta^{k}$ indicate the estimated plough coefficient for outcome variable $k$ and $\sigma^{k}$ the standard deviation of outcome $k$. Then, the average effect size is equal to $\frac{1}{K} \sum_{k=1}^{K} \frac{\beta^{k}}{\sigma^{k}}$, where $K$ is the total number of outcome variables. To properly calculate the sample variance of the AES, the coefficients $\beta^{k}$ are jointly estimated in a seemingly unrelated regression framework. ${ }^{20}$ The AES estimates confirm the findings when examining the outcomes individually: historical plough use is associated with less female participation in activities outside of the home today. As well, the implied magnitudes are similar. According to the AES estimate, a one-standard-deviation increase in plough use is associated with an average decrease (for the three outcomes) of 0.40 standard deviations.

An alternative way to assess the magnitude of the estimates is to calculate the proportion of the total variation they explain. By this metric as well, historical plough use explains a sizable proportion of differences in gender roles across countries. When female labor force participation is the dependent variable (column 1 of Table 2), the inclusion of the historical plough use variable increases the $R$-squared by 0.086 (from 0.326 to 0.412). Therefore, traditional plough use accounts for $8.6 \%$ of the total variation in FLFP and $12.8 \%$ of the residual variation in FLFP unaccounted for by the control variables. ${ }^{21}$ For the share of firms with female ownership, traditional plough use accounts for $5 \%$ of the total variation and $6 \%$ of the residual variation. For the participation of women in politics, historical plough use explains $3 \%$ of the total variation and $4 \%$ of the residual variation.

Although we do not report them explicitly in here, we find that the estimated coefficients for the control variables are generally as expected. ${ }^{22}$ For example we find evidence of a Ushaped relationship between per capita income and female labor force participation, as well as the other outcomes. This is consistent with previous studies that also find this same non-monotonic relationship (Goldin, 1995). We also find that countries that experience a period of communism have higher rates of female labor force participation.

\footnotetext{
${ }^{20}$ See Clingingsmith, Khwaja and Kremer (2009) for an alternative application and further details.

${ }^{21}$ This is calculated as: $(0.412-0.326) /(1-0.326)=0.128$ or $12.8 \%$.

${ }^{22}$ The estimates for the controls are available upon request.
} 
Robustness to alternative plough measures

Using either of the two methods for imputing missing language data yields estimates that are qualitatively identical to the estimates using our baseline variable. As reported in Appendix Table A2, the alternative measures yield nearly identical point estimates that are highly significant. As a final check to ensure that our findings are not being driven by measurement error, we omit 17 countries that have a significant proportion of missing language data. The countries include Australia, Argentina, Bolivia, Brazil, Chile, Colombia, Costa Rica, Ecuador, Guatemala, Honduras, Mexico, New Zealand, Nicaragua, Panama, Paraguay, Peru and Venezuela. The estimates, reported in Appendix Table A3, show that the impact of the plough remains robust to this check.

\section{The persistence of female labor force participation}

To this point, we have shown that historical plough use is associated with less female participation in agriculture historically and with less female participation in the labor force today. These two correlations suggest long-term persistence in female participation in activities outside of the home. As a check for this, we regress female labor force participation today on the measure of women's historical participation in agriculture constructed from the Ethnographic Atlas. The regression also controls for our full set of covariates from equation (2) above. The partial correlation plot, showing the relationship between historical female participation in agriculture and FLFP today, is shown in Figure 6. As is apparent from the figure, there is strong persistence over time. Female labor force participation today and female participation in agriculture in the past are very strongly correlated.

In light of existing studies, this persistence is perhaps surprising. In fact, Goldin and Sokoloff (1984) document that within the Northeastern United States, the low relative productivity of women and children in agriculture (and hence their low participation) spurred industrialization and their active participation in the manufacturing sector. In their setting, female labor force participation in agriculture was inversely related to participation in manufacturing, suggesting a lack of continuity of female labor force participation overtime as industrialization occurs. However, our results show that this example does not appear to be general. Instead, areas with low female participation in agriculture and plough use historically (because of the persistence of 


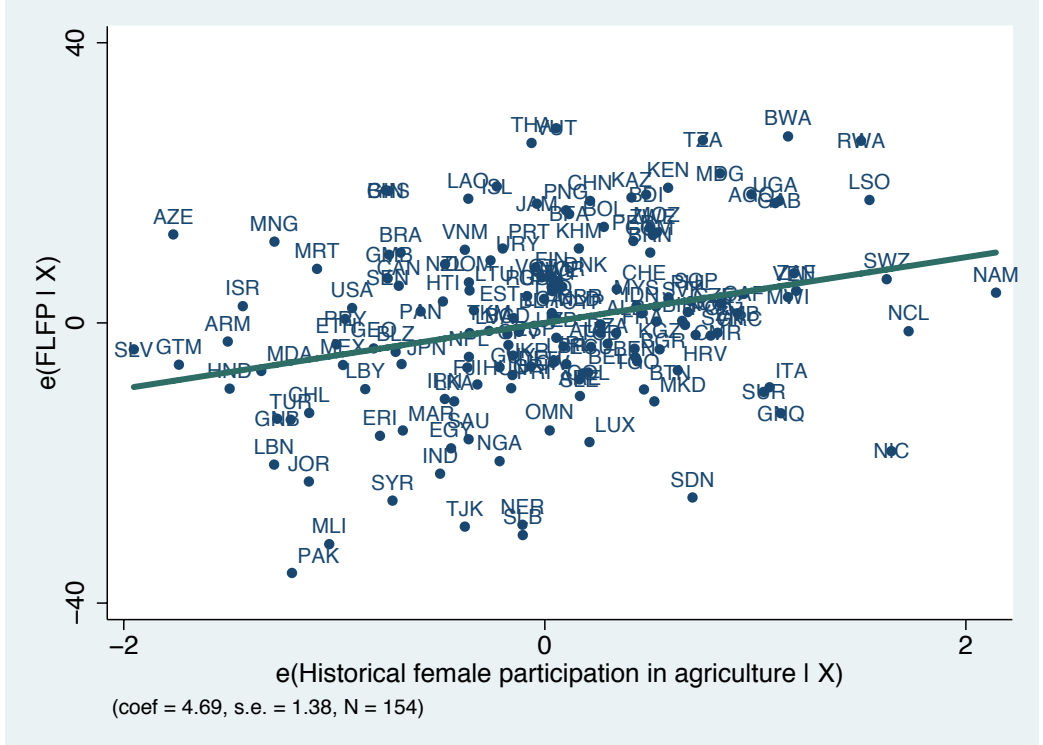

Figure 6: Historical female participation in agriculture and current FLFP.

norms and beliefs) today continue to have low levels of female participation in activities outside of the home, even after the economy moves out of agriculture and into industry.

\section{Controlling for alternative hypotheses}

We now test the robustness of our estimates to alternative determinants of gender roles that have been suggested by various scholars. A prominent alternative explanation for the origins of gender role differences was proposed by Frederick Engels (1902). He argued that gender inequality arose as a result of the intensification of agriculture, which resulted in the emergence of private property, which was monopolized by men. The control of private property allowed men to subjugate women and to introduce exclusive paternity over their children, replacing matriliny with patrilineal descent, making wives even more dependent on husbands and their property. As a consequence, women were no longer active and equal participants in community life.

We account for this potential mechanism by controlling for a variable that measures the proportion of a country's ancestors practicing intensive agriculture. We also control for the proportion of a country's population with ancestors without land inheritance rules, which we take as an indicator for the absence of property rights in land. Lastly, we control for two variables that capture the proportion of a country's ancestors with patrilocal post-marital residence rules and with matrilocal rules. These capture the extent to which societies were matrilineal versus 
patrilineal. All of the controls are constructed using the Ethnographic Atlas and in the same manner as the historical plough use and other ethnographic control variables. ${ }^{23}$

Columns $1-3$ of Table 3 report estimates of equation (2) with the additional controls included. For brevity, we only report estimates with female labor force participation as the dependent variable. (The estimates for the other outcomes variables are also robust to the inclusion of the additional controls.) The estimated impact of traditional plough use remains robust to the inclusion of the additional controls: the coefficient remains negative and statistically significant, and its magnitude changes little from the baseline value of 16.5 .

It has been hypothesized that cultures with large-extended families typically have more hierarchical and less egalitarian structures, and since hierarchies tend to be dominated by men, this results in a subordinate status of women (Engels, 1902, Boserup, 1970, Barry, Bacon and Child, 1957). ${ }^{24}$ We control for the potential impact of family structures by controlling for the proportion of a country's ancestors that lived in nuclear or extended families. ${ }^{25}$ Estimates with these additional controls are reported in column 4. The estimate for historical plough use remains robust.

It is possible that the status of women is also affected by the extent to which a society participates in certain non-agricultural activities, which are less suitable to female involvement. Likely candidates include the hunting and herding of large animals, which may require significant strength. We construct measures of the proportion of subsistence activities accounted for by hunting and by the herding of large animals. ${ }^{26}$ As shown in column 5, the inclusion of these controls has little impact on the estimated effect of past plough use.

A potentially important determinant of differences in gender roles is religion. We check the robustness of our estimates by controlling for five variables that measure the proportion of a country's population that is: Catholic, Protestant, other Christian, Muslim, and Hindu. ${ }^{27}$ As shown in column 6, the estimated impact of the plough remains robust to controlling for current religion.

\footnotetext{
${ }^{23}$ The controls are derived from variables v12, v28 and v75 from the Ethnographic Atlas. Full details of their construction are provided in the paper's appendix.

${ }^{24} \mathrm{~A}$ similar but different theory stresses competence rather than authority. In large families with many adults, a gender division of labor can more easily develop. In nuclear families with only a husband and a wife, it is more likely that either adult will need to substitute for the other. Therefore, the wife will be involved in activities ordinarily done by men (Whyte, 1978).

${ }^{25}$ The information is taken from variable v8 of the Ethnographic Atlas.

${ }^{26}$ The variables are constructed from variables v2 and v4 of the Ethnographic Atlas.

27The data are taken from McCleary and Barro's (2006) Religion Adherence dataset.
} 
Table 3: Robustness of OLS estimates to alternative controls.

\begin{tabular}{|c|c|c|c|c|c|c|}
\hline & \multicolumn{6}{|c|}{ Dependent variable: FLFP } \\
\hline & (1) & $(2)$ & (3) & $(4)$ & $(5)$ & $(6)$ \\
\hline Historical plough use & $\begin{array}{c}-14.734^{* * *} \\
(4.856)\end{array}$ & $\begin{array}{c}-16.814^{* * *} \\
(3.769)\end{array}$ & $\begin{array}{c}-17.073 * * * \\
(3.568)\end{array}$ & $\begin{array}{c}-14.570 * * * \\
(3.568)\end{array}$ & $\begin{array}{c}-15.417^{* * *} \\
(3.692)\end{array}$ & $\begin{array}{c}-12.041^{* * *} \\
(3.967)\end{array}$ \\
\hline Practices intensive agriculture & yes & & & & & \\
\hline Absence of private property & & yes & & & & \\
\hline Patrilocal society, matrilocal society & & & yes & & & \\
\hline Nuclear family, extended family & & & & yes & & \\
\hline Proportion of subsistence from: hunting, herding & & & & & yes & \\
\hline Prop of pop belonging to five major religions & & & & & & yes \\
\hline Baseline historical and contemporary controls & yes & yes & yes & yes & yes & yes \\
\hline Observations & 159 & 156 & 159 & 159 & 159 & 157 \\
\hline R-squared & 0.41 & 0.41 & 0.42 & 0.46 & 0.43 & 0.57 \\
\hline & $(7)$ & $(8)$ & (9) & $(10)$ & $(11)$ & $(12)$ \\
\hline Historical plough use & $\begin{array}{c}-16.435^{* * *} \\
(3.536)\end{array}$ & $\begin{array}{c}-15.767^{* * *} \\
(3.538)\end{array}$ & $\begin{array}{c}-18.474^{* * *} \\
(4.112)\end{array}$ & $\begin{array}{c}-16.467^{* * *} \\
(3.564)\end{array}$ & $\begin{array}{c}-16.519 * * * \\
(3.592)\end{array}$ & $\begin{array}{c}-15.375^{* * *} \\
(3.844)\end{array}$ \\
\hline Oil production per capita & yes & & & & & \\
\hline Trade/GDP & & yes & & & & \\
\hline Agric., manuf. and services share of GDP & & & yes & & & \\
\hline Years of civil conflicts (1816-2007) & & & & yes & & \\
\hline Years of interstate conflicts (1816-2007) & & & & & yes & \\
\hline Fraction of European descent & & & & & & yes \\
\hline Baseline historical and contemporary controls & yes & yes & yes & yes & yes & yes \\
\hline Observations & 157 & 159 & 157 & 157 & 157 & 151 \\
\hline R-squared & 0.43 & 0.42 & 0.42 & 0.41 & 0.41 & 0.42 \\
\hline
\end{tabular}

Ross (2008) challenges the view that religion - particularly Islam - has an important impact on gender roles. He argues instead for the importance of a country's endowment of oil reserves. According to his hypothesis, oil causes a country's domestic currency to strengthen, making exports less competitive and causing a decline in light manufacturing, a sector particularly wellsuited for female employment. We account for this possibility by controlling for per capita oil production and the trade-to-GDP ratio, both measured in 2000. We also control for the economic structure of each country by including three variables that capture the share of GDP accounted for by agriculture, manufacturing and services. ${ }^{28}$ Estimates with the additional controls are reported in columns 7-9. The impact of the plough remains robust.

Differences in gender roles could potentially be influenced by differences in the prevalence of warfare across societies. However, a priori, the direction of the effect is unclear (see Whyte, 1978). Involvement in warfare may cause societies to become more hierarchical and male dominated, suggesting a negative relationship between conflict and female work outside the home. On the other hand, being involved in warfare can generate a greater need for female involvement outside of the home. We control for the potential impacts of warfare, by calculating, for each country, the

\footnotetext{
${ }^{28}$ The data are from the World Development Indicators, except for the oil production data which is from BP Oil (2006).
} 
number of years since 1816 (the first year data are available) that the country was involved in either internal or interstate warfare. ${ }^{29}$ The results, reported in columns 10 and 11 , show that the impact of plough use robust to controlling for warfare..$^{30}$

The last factor that we consider is motivated by the fact that country-level ancestral plough use is affected by historical European migration. European ancestry may have an effect on female labor force participation independent of historical plough use. We address this possibility by controlling for the fraction of each country's population in 2000 with ancestors that came from Europe $^{31}$ As reported in column 12, the estimates remain robust to controlling for European ancestry. $3^{2}$

Overall, the estimated impact of the plough remains highly robust across the various specifications reported in Table 3. The coefficient is always negative and statistically significant, and the point estimates remain stable, ranging from -0.12 to -0.18 .

\section{B. Individual-level estimates}

We now turn to our specification that examines variation across individuals, linking them to a tradition of plough agriculture using the district they live in. The analysis relies on data from the World Value Survey (WVS), a compilation of national individual-level surveys on a wide variety of topics, including attitudes and preferences, as well as information on standard demographic characteristics, such as gender, age, education, labor market status, income, religion, etc. ${ }^{33}$ Using the WVS we construct, for females, an indicator variable that equals one if she is in the labor force, which is defined as full-time, part-time or self-employment. Women are not in the labor force if they report being retired, a housewife or a student. 34

We also examine two measures of individuals' attitudes (male and female) about the appropriate role of women in society. The first measure is based on each respondent's view of the following

\footnotetext{
${ }^{29}$ The data are from version 4 of the Correlates of War Database.

${ }^{30}$ In Table 3, we control for the two types of warfare separately. Including both controls simultaneously does not alter the conclusion. In this case the coefficient is equal to -16.512 with a standard error of $3 \cdot 578$.

${ }^{31}$ The measure is taken from Nunn and Puga (2011), who calculate the variable using Putterman and Weil's (2010) World Migration Matrix.

${ }^{32}$ An alternative, more brut-force strategy, is to omit all European and the neo-European countries (Australia, New Zealand, Canada, the US) from the sample. As reported in Appendix Table A4, the results also remain robust to this check.

33Five waves of the WVS were carried out between 1981 and 2007. In our analysis, we use the four most recent waves of the survey, since the first wave does not contain information on the district in which the respondent lives. Because regional classifications often vary by wave, we use the wave with the most finely defined location data.

34The results are qualitatively identical if we exclude retired women and students from the sample.
} 
statement: "When jobs are scarce, men should have more right to a job than women". The respondents are then asked to choose between agree, disagree, neither or don't know. We omit observations for which the respondents answered 'neither' or 'don't know', and code 'disagree' as $\mathrm{o}$ and 'agree' as 1.35 Therefore, the constructed variable is increasing in the extent to which a respondent's view is characterized by gender inequality.

We also consider a second variable derived from a survey question based on the following statement: "On the whole, men make better political leaders than women do". Respondents are then asked to choose between 'strongly disagree', 'disagree', 'agree', 'agree strongly', or 'don't know'. We omit observations in which the respondent answered 'don't know' and create a variable that takes on the value of 1 for 'strongly disagree', 2 for 'disagree', 3 for 'agree' and 4 for 'agree strongly'. This variable, like the first, is increasing in the respondent's view of gender inequality.

An appealing aspect of the two subjective belief-based variables is that they provide measures of the values that form the foundation of the objective outcome variables from the cross-country analysis. The first question reflects differences in individual beliefs about whether women should have equal access to jobs, which likely affect observed differences in female labor force participation rates across countries. The second question reflects values about the ability of women to take on roles of leadership and responsibility, which likely affects observed differences in female participation in politics and female firm ownership and management. Therefore, there is a close link between the objective measures from the country-level analysis and the subjective measures in the individual-level analysis.

Examining the three outcomes - female participation in the labor force, attitudes about female employment, and attitudes about female leadership - we estimate the following individual-level equation:

$$
y_{i, d, c}=\alpha_{r(c)}+\beta \text { Plough }_{d}+\mathbf{X}_{c}^{\mathbf{C}} \boldsymbol{\Gamma}+\mathbf{X}_{d}^{\mathbf{H}} \boldsymbol{\Pi}+\mathbf{X}_{i} \boldsymbol{\Phi}+\varepsilon_{i, d, c}
$$

where $i$ denotes an individual, $d$ denotes a district within a country $c$, and $r(c)$ denotes the

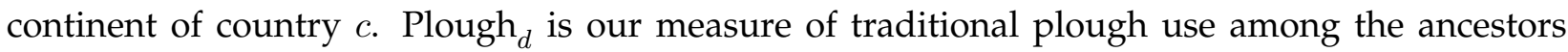
of individuals living in district $d . \mathbf{X}_{c}^{\mathbf{C}}$ are the same contemporary country-level controls as in

\footnotetext{
${ }^{35}$ We omit observations that respond 'neither' because it is ambiguous whether this represents an intermediate view or whether they have chosen not to answer the question or whether they do not know their answer. If we interpret this response as reflecting an intermediate position and code a variable that takes on the values 0,1 , and 2 , then we obtain qualitatively identical results to what we report here.
} 
Table 4: Individual-level OLS estimates.

\begin{tabular}{lcccc}
\hline \hline & \multicolumn{4}{c}{ Dependent variables: } \\
\cline { 2 - 5 } & FLFP & $\begin{array}{c}\text { When jobs are } \\
\text { scarse }\end{array}$ & $\begin{array}{c}\text { Men better } \\
\text { political leaders }\end{array}$ & $\begin{array}{c}\text { Average effect size } \\
\text { (AES) }\end{array}$ \\
\cline { 2 - 5 } Historical plough use & $(1)$ & $(2)$ & $(3)$ & $(4)$ \\
& $-0.214^{* * *}$ & $0.245^{* * *}$ & $0.397^{* * *}$ & $0.451^{* * *}$ \\
Individual controls & $(0.034)$ & $(0.029)$ & $(0.075)$ & $(0.063)$ \\
Contemporary country controls & & & & \\
Historical district controls & yes & yes & yes & yes \\
Continent fixed effects & yes & yes & yes & yes \\
Observations & yes & yes & yes & yes \\
R-squared & 38,832 & yes & yes & yes \\
\hline
\end{tabular}

Notes: The table reports OLS estimates, with standard errors clustered at the country level. Individual controls are age, age squared, education, gender (for gender attitudes only), marital status, and income. Contemporary country controls include In income, In income squared and a communism indicator variable. Historical district controls include agricultural suitability, domesticated animals, tropical areas, political hierarchies, and economic complexity. The AES reported in column 4 is for the two subjective belief measures from columns 2 and $3 . * * *, * *$ and $*$ indicate significance at the 1,5 and $10 \%$ levels.

equation (2), and $\mathbf{X}_{d}^{\mathbf{H}}$ includes the same historical ethnographic variables as in equation (2), but measured at the district level rather than the country level. $\mathbf{X}_{i}$ denotes current individual-level controls: age, age squared, as well as fixed effects for marital status, educational attainment, and income levels. The equation also includes continent fixed effects, denoted $\alpha_{r(c)}$. To be as conservative as possible, we cluster the standard errors at the country level.

Table 4 reports OLS estimates of equation (3). Consistent with the country-level estimates, we find a negative relationship between historical plough use and female labor force participation today, and a positive relationship between historical plough use and current attitudes reflecting gender inequality. In terms of the magnitude of the effects, they are similar to the cross-country estimates. A one-standard-deviation increase in the plough variable implies a reduction in female labor force participation of 0.09 or 9 percent (which is roughly equal to $16 \%$ of the sample average) and an increase in the female employment and female leadership gender attitudes variables of 0.10 and 0.21 , respectively. These are $21 \%$ and $8 \%$ of the sample averages.

\section{IV estimates}

There is a number of concerns with the OLS estimates reported to this point. One is that locations that historically had attitudes prone to less equal gender roles may have been more likely to invent 
or adopt the plough. This would bias our OLS estimates away from zero. It is also possible that locations that were economically more developed were more likely to have adopted the plough. Since these areas today are richer and more prone to attitudes about gender role equality, this would tend to bias our OLS towards zero.

Our first strategy to address these, and related, concerns is to control for observable characteristics. This is done in the previous section. In this section, we pursue an alternative strategy using instrumental variables. As instruments we exploit one determinant of historical plough use that has been emphasized in the anthropological literature: the type of crops grown in a particular location (Pryor, 1985).

The primary benefit of the plough is that it facilitates the cultivation of larger amounts of land over a shorter period of time. This capability is more advantageous for crops that require specific planting conditions that are only met during narrow windows of time or for crops that require larger tracts of land to cultivate a given amount of calories. The benefit of the plough is also reduced for crops grown in swampy, sloped, rocky, or shallow soils, all of which make the plough less efficient or impossible to use. Taking these factors into consideration, Pryor (1985) has classified crops into those whose cultivation benefits greatly from the adoption of the plough - he calls these plough positive crops - and those whose cultivation benefits less - called plough-negative crops. Plough-positive crops, which include wheat, teff, barley and rye, tend to be cultivated on large expanses of land (per calorie of output) that is flat, deep, with soil that are not too rocky or swampy, and have shorter growing seasons. Plough negative crops, which include sorghum, maize, millet, roots and tubers, and tree crops, tend to yield more calories per acre, have longer growing seasons, and can be cultivated on more marginal land (Pryor, 1985, p. 732).

Because the cultivation of plough-positive and plough-negative crops is an endogenous outcome, we do not use this as our instrument. Instead, we measure geo-climatic conditions that are unaffected by human actions, but which impact the suitability of a location for growing both types of crops. Our strategy uses two instruments. The first is a measure of the average suitability of the location of each observation's ancestors for cultivating plough positive cereal crops - wheat, barley and rye. The second is the same measure of ancestral suitability, but for cultivating millet and sorghum, which are plough-negative cereal crops. We intentionally choose to consider this set of crops because they are similar in many other dimensions except for the extent to which 
they benefit from the use of the plough. Both sets of crops are cereals that have been cultivated in the Eastern Hemisphere since the Neolithic revolution (Mazoyer and Roudart, 2006, pp. 71-99). Both sets of crops require similar preparations for consumption, all being used for flour, porridge, bread or in beverages (Recklein, 1987). Both sets also produce similar yields and therefore neither clearly dominates the other in terms of the population it can support (Pryor, 1985, p. 732).

We obtain information on the suitability of a location for cultivating the plough-positive and plough-negative cereal crops from the FAO's Global Agro-Ecological Zones (GAEZ) 2002 database (Fischer et al., 2002). The database reports suitability for the cultivation of numerous crops for 5 arc minutes by 5 arc-minute grid-cell globally. The measures are constructed from measures of the geo-climatic characteristics of a location: precipitation, frequency of wet days, mean temperature, daily temperature range, vapor pressure, cloud cover, sunshine, ground-frost frequency, wind speed, soil slope, and soil characteristics. The data are then combined with the specific growing requirements of crops to produce a measure of whether the crop can be grown in a location, and if so, how productively. It is important to note that the models of crop growth are based solely on previously established technical requirements and constraints for crop growth. The model's parameters, and the final measures, are not affected by where crops are actually cultivated. As well, the final estimates are not simple functions of the geographic characteristics used, but are based on precise, highly non-linear crop-specific models of evapotranspiration, water-balance, temperature profiles, temperature growing periods, length of growing period, thermal regimes, etc. This last point is particularly important as it allows us to check the robustness of our IV results to controlling for important geo-climatic characteristics which may be different in plough-positive and plough-negative environments. ${ }^{36}$

We construct the instruments by first identifying the land traditionally inhabited by each ethnic group in the Ethnographic Atlas. We continue to use all land within 200 kilometers of an ethnic group's centroid and measure the amount of land within this area that can grow each of the cereal crops that comprise the instruments. ${ }^{37}$ Let $x_{e}^{w}, x_{e}^{b}, x_{e}^{r}, x_{e}^{s}$, and $x_{e}^{m}$ be the amount of land that can cultivate wheat, barley, rye, sorghum and millet, respectively. Further, let $x^{\text {all }}$ be the amount of land that could grow any crop (i.e., the amount of arable land). The ethnicity-level measures of suitability for plough-positive crops is given by: $\operatorname{Area}_{e}^{p o s}=\frac{1}{3}\left(x_{e}^{w}+x_{e}^{b}+x_{e}^{r}\right) / x_{e}^{\text {all }}$. While ethnicity-

\footnotetext{
${ }^{36}$ For a detailed discussion of the data and its use in a different application see Nunn and Qian (2011).

37The GAEZ database measures suitability as a proportion of maximum attainable yield. We define locations that obtain at least $40 \%$ of the maximum yield as suitable. The results are robust to the use of other thresholds.
} 
level measure of suitability for plough-negative crops is: $A r e a_{e}^{n e g}=\frac{1}{2}\left(x_{e}^{s}+x_{e}^{m}\right) / x_{e}^{\text {all }}$. Intuitively, the instruments measure the average suitability for each type of crop, normalized by the overall suitability for cultivation in general. ${ }^{38}$

Using the procedure explained in equation (1), we then construct district- and country-level averages of our plough-positive and plough-negative instruments. Intuitively, the instruments measure the proportion of the population with ancestors that had a climate that could grow plough-positive cereals (wheat, barley and rye) and the proportion that could grow plough negative cereals (sorghum and millet).

To provide the reader with a better sense of the instruments, Figure 7 shows the parts of the world that are classified as being suitable for the cultivation of the plough positive cereals - wheat, barley and rye - while Figure 8 shows suitability for the plough-negative cereals - millet and sorghum. A number of facts are apparent from the maps. First, there are many parts of the world that can grow plough-positive crops, but not plough-negative crops and vice versa. This provides an indication that the instruments may have variation independent from each other and therefore some predictive power. Second, relative to plough-positive crops, plough-negative crops appear to be relatively better suited for tropical and subtropical climates and plough-positive crops better suited for temperate climates. If these differences in climate affect gender attitudes today through channels other than past plough use, then the exclusion restriction will not be satisfied. Recall that the controls already include the proportion of land, historically inhabited by an ethnic group, that was tropical or subtropical. As well, in the analysis below we explicitly address this concern by exhaustively controlling for additional geographic characteristics that may be correlated with the suitability instruments. 39

\footnotetext{
${ }^{38}$ Our procedure assumes that the GAEZ data provide an unbiased measure of historical suitability. In a different context, Nunn and Qian (2011) provide evidence of the validity of this assumption by showing that the GAEZ suitability measure for potatoes is highly correlated with historical potato production.

${ }^{39} \mathrm{An}$ important final point arises from the fact that the plough-positive and plough-negative cereals used in the construction of our instruments were all originally grown in the Eastern hemisphere and were not cultivated in the Americas until after 1500. This is not a concern to identification, but it is a fact that makes the first stage relationship weaker than it would be otherwise. For the large proportion of the population in the Americas whose ancestors are from the Eastern hemisphere, the instrument will provide predictive power. It is only for the indigenous populations of the Americas that the instrument will not affect plough adoption. This should be kept in mind when interpreting the IV estimates as a local average treatment effect (LATE). In other words, the estimates are an average effect among the ethnic groups whose plough adoption was affected by the geo-climatic suitability for growing the cereal crops.
} 


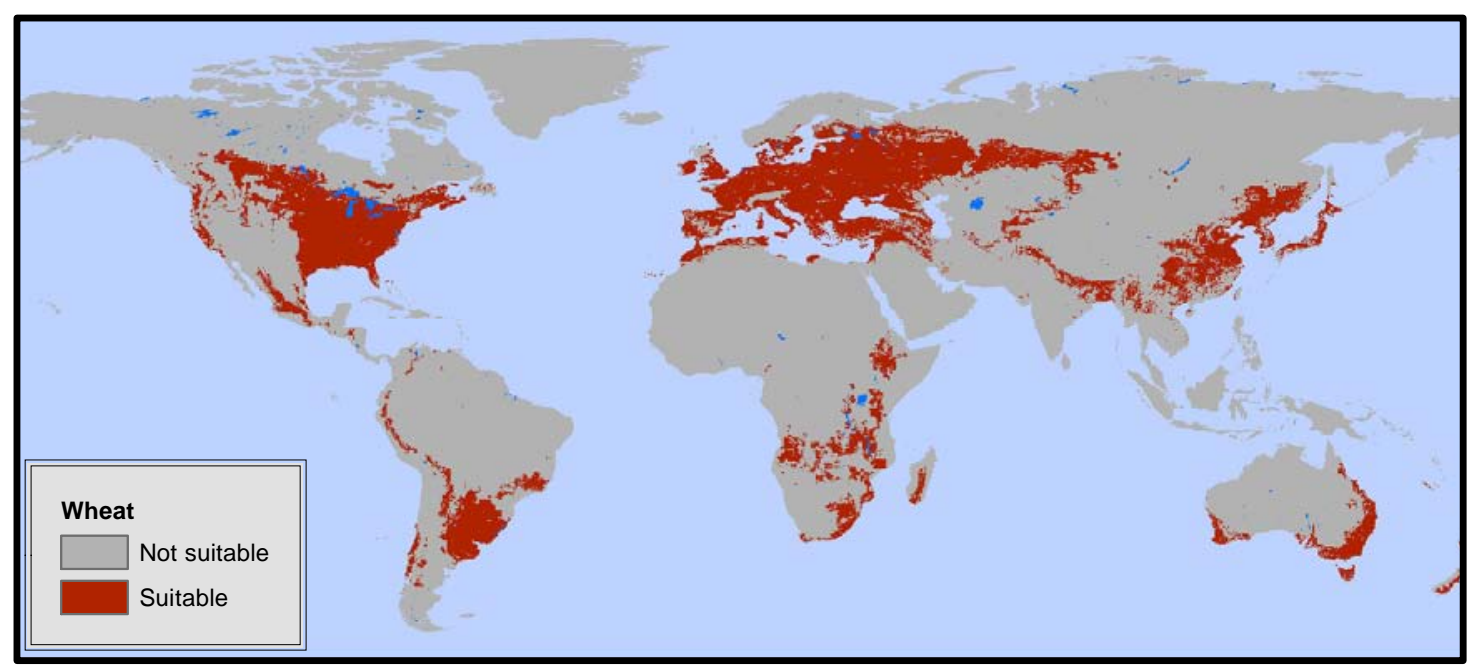

(a) Wheat suitability

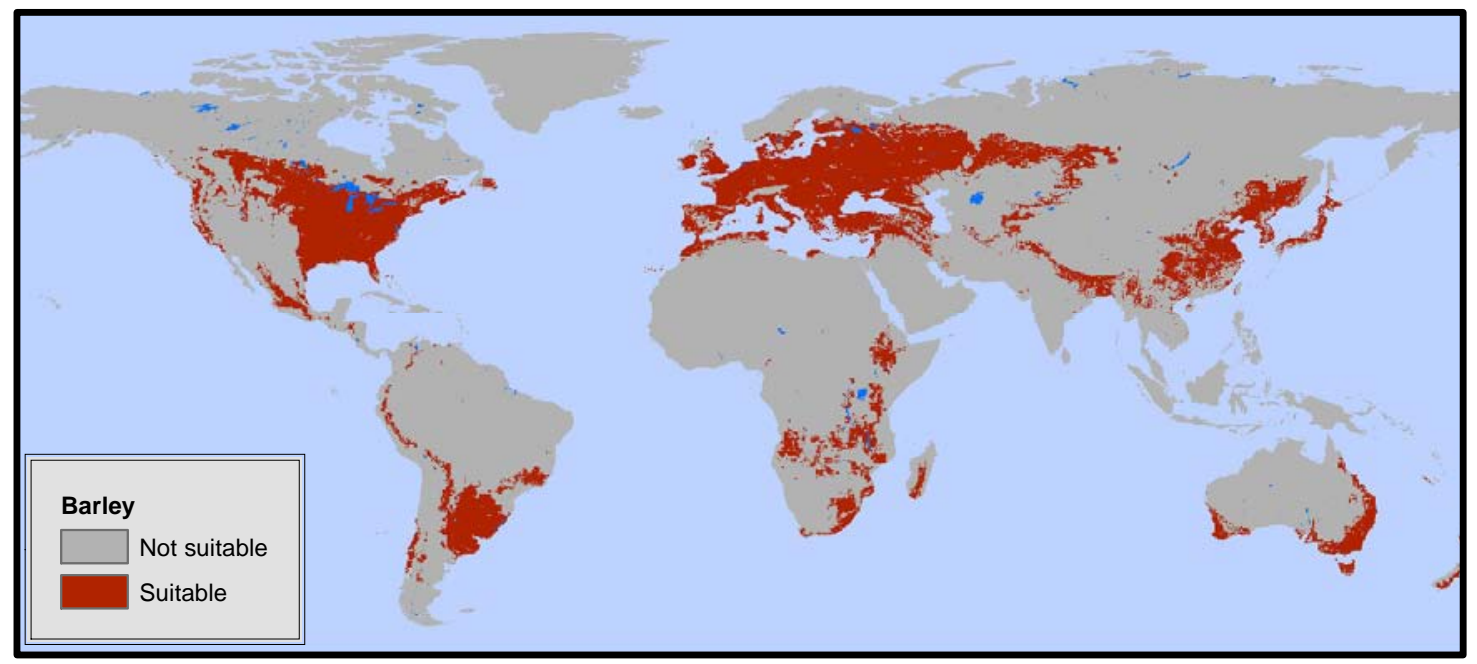

(b) Barley suitability

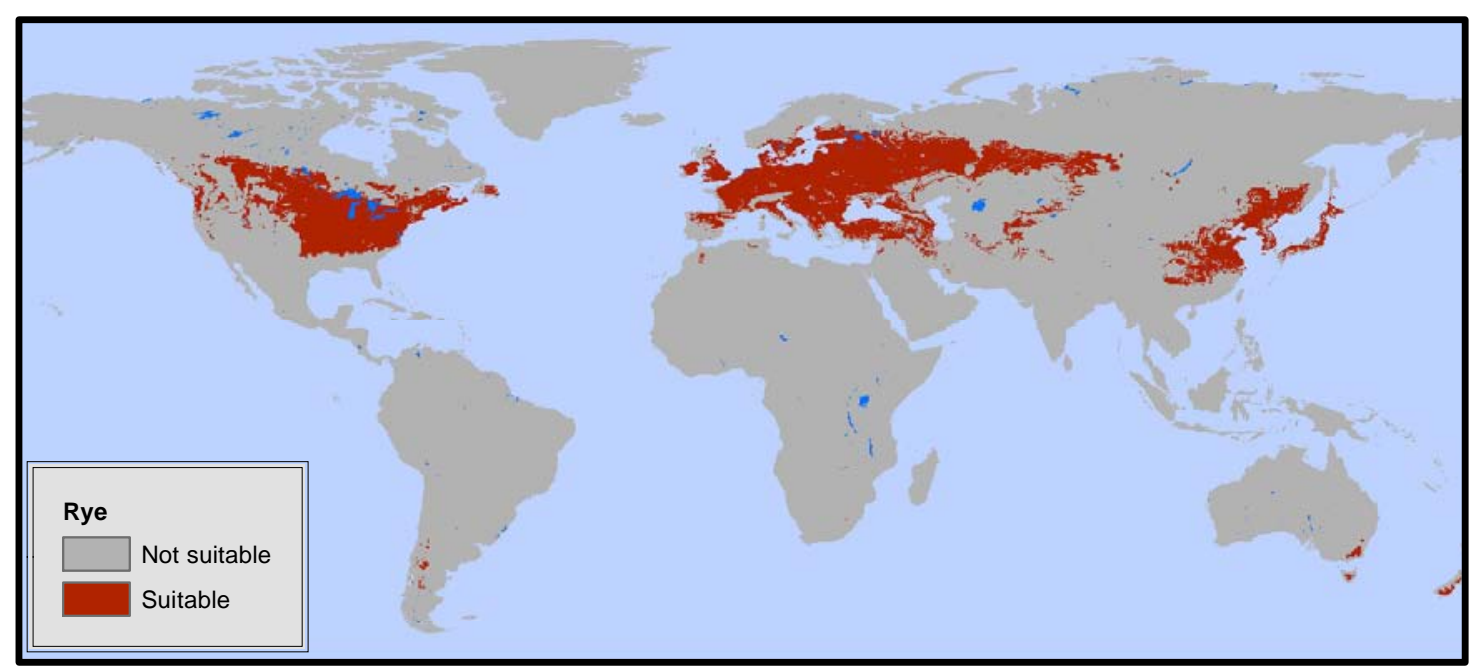

(c) Rye suitability

Figure 7: Maps displaying the global suitability of plough-positive crops, wheat, barley and rye. 


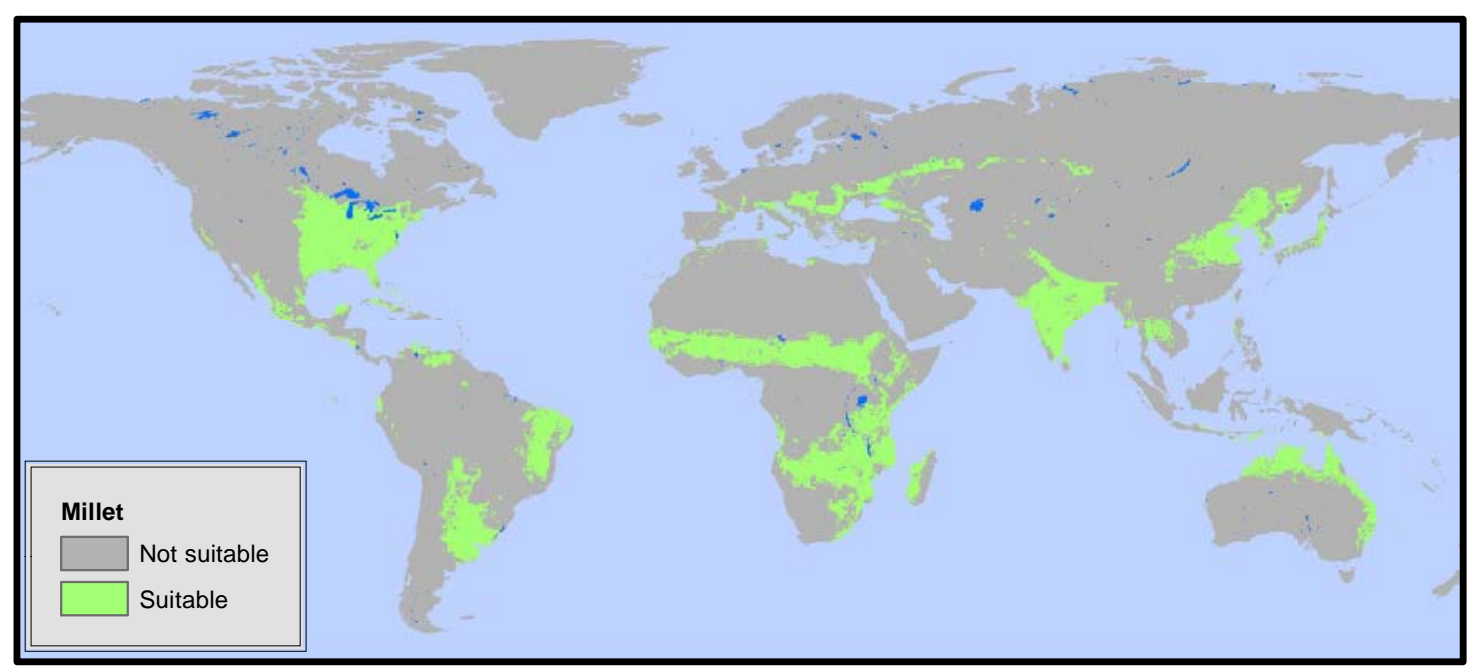

(a) Millet suitability

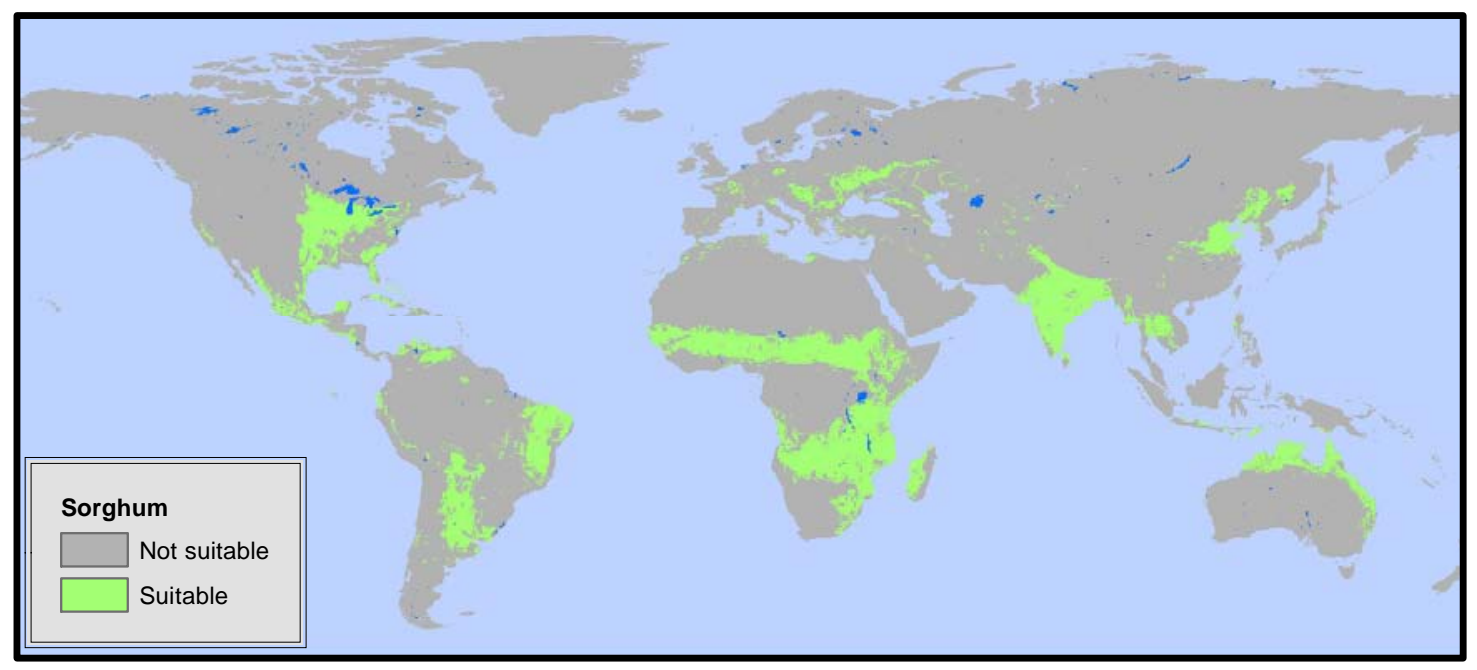

(b) Sorghum suitability

Figure 8: Maps displaying the global suitability of plough-negative crops, millet and sorghum. 
Table 5: Country level IV estimates.

\begin{tabular}{|c|c|c|c|c|c|c|c|c|}
\hline & \multicolumn{8}{|c|}{ Panel A. Second stage. Dependent variable: } \\
\hline & \multicolumn{2}{|c|}{$\begin{array}{c}\text { Femal labor force } \\
\text { participation }\end{array}$} & \multicolumn{2}{|c|}{$\begin{array}{l}\text { Share of firms with some } \\
\text { female ownership }\end{array}$} & \multicolumn{2}{|c|}{ Females in politics } & \multicolumn{2}{|c|}{ Average effect size (AES) } \\
\hline & $(1)$ & $(2)$ & (3) & $(4)$ & (5) & $(6)$ & $(7)$ & $(8)$ \\
\hline Historical plough use (2SLS) & $\begin{array}{c}-25.853^{* *} \\
(10.051)\end{array}$ & $\begin{array}{c}-26.423^{* *} \\
(12.465)\end{array}$ & $\begin{array}{c}-19.939 * \\
(11.932)\end{array}$ & $\begin{array}{c}-26.274^{*} \\
(14.439)\end{array}$ & $\begin{array}{c}-16.820^{*} \\
(9.243)\end{array}$ & $\begin{array}{c}-23.089 * \\
(12.331)\end{array}$ & $\begin{array}{c}-1.451 * * * \\
(0.467)\end{array}$ & $\begin{array}{c}-1.946 * * * \\
(0.635)\end{array}$ \\
\hline Historical plough use (LIML) & -27.099 & -28.25 & -28.761 & -43.12 & -16.826 & -23.16 & & \\
\hline $\mathrm{p}$-value & 0.01 & 0.03 & 0.03 & 0.02 & 0.05 & 0.03 & & \\
\hline CLR intervals & {$[-54.88,-7.02]$} & {$[-66.24,-3.47]$} & {$[-71.65,-2.70]$} & {$[-142.60,-6.77]$} & {$[-47.06,0.29]$} & {$[-75.07,-2.55]$} & & \\
\hline Historical controls & yes & yes & yes & yes & yes & yes & yes & yes \\
\hline Contemporary controls & yes & yes & yes & yes & yes & yes & yes & yes \\
\hline Continent FEs & no & yes & no & yes & no & yes & no & yes \\
\hline Observations & 157 & 157 & 104 & 104 & 124 & 124 & 133 & 133 \\
\hline \multirow[t]{2}{*}{ R-squared } & 0.39 & 0.43 & 0.01 & 0.13 & 0.17 & 0.05 & & \\
\hline & \multicolumn{8}{|c|}{ Panel B. First stage. Dep var: Historical plough use } \\
\hline \multirow[t]{2}{*}{ Plough-positive environment } & $0.412 * * *$ & $0.377^{* * *}$ & $0.656 * * *$ & $0.561^{* * *}$ & $0.401 * * *$ & $0.340 * * *$ & & \\
\hline & $(0.119)$ & $(0.101)$ & $(0.150)$ & $(0.143)$ & $(0.140)$ & $(0.117)$ & & \\
\hline \multirow[t]{2}{*}{ Plough-negative environment } & -0.120 & -0.079 & -0.017 & 0.001 & -0.032 & -0.026 & & \\
\hline & $(0.091)$ & $(0.075)$ & $(0.101)$ & $(0.075)$ & $(0.103)$ & $(0.087)$ & & \\
\hline Equality of coefficients ( $p$-value) & 0.00 & 0.00 & 0.00 & 0.00 & 0.00 & 0.01 & & \\
\hline F-stat (excluded instruments) & 10.76 & 7.90 & 11.68 & 7.71 & 5.63 & 4.54 & & \\
\hline Hausman test ( $p$-value) & 0.15 & 0.19 & 0.44 & 0.29 & 0.18 & 0.09 & & \\
\hline
\end{tabular}

\section{A. Country-level estimates}

Table 5 reports IV estimates of the specifications from Table 2. The first stage estimates are reported in the lower panel and the second stage estimates are in the top panel. The first stage estimates show that the historical suitability for the cultivation of plough-positive cereals is always positively correlated with the adoption of the plough, while suitability for the cultivation of plough-negative cereals is generally negatively correlated with plough use. In all specifications, the difference between the two coefficients is statistically significant. The $F$-test for joint significance of the two instruments is also reported in the table. The $F$-statistics range from about $5^{-11}$, suggesting that for some specifications there is a potential concern about weak instruments. For this reason we also report conditional likelihood ratio (CLR) confidence intervals and LIML estimates in addition to the regular 2SLS estimates.

The IV estimates, reported in panel A of the table, confirm the OLS estimates. Historical plough use is associated with less female labor force participation, less female ownership of firms, and less female participation in politics. The magnitude of the IV coefficients are consistently greater than the OLS estimates. This is potentially explained by selection arising from the endogeneity of plough adoption. All else equal, historically advanced societies were more likely 
to adopt the plough. Further, they are more likely to also be advanced today with higher per capita incomes and more female participation in the labor market. Therefore, selection introduces a positive relationship between historical plough use and female labor force participation today, biasing the negative OLS estimates towards zero.

The IV estimates rest on the assumption that holding overall agricultural suitability constant, the specific type of cereal crop that a location could grow only impacts long-term gender attitudes through the past adoption of the plough. There are a number of potential concerns with this assumption. The first is that the difference between plough-positive and plough-negative environments may be correlated with geographic features that affect gender attitudes today through channels other than the plough. We check the robustness of our results to this concern by controlling for geographic characteristics that are potentially correlated with the suitability of the environment for plough-positive and plough-negative crops. Our controls include terrain slope, soil depth, average temperature and average precipitation of locations inhabited by each country's ancestors. Slope is measured as percent (i.e., rise over run). The soil depth control is the fraction of land that has no, few or slight soil depth constraints for cultivation. Average temperature is the average daily temperature (measured in degrees Celsius) between 1950 and 1959. Precipitation is the average monthly rainfall (in $\mathrm{mm}$ ) over the same time period.

As reported in Table 6, the IV estimates remain robust to the inclusion of these geo-climatic characteristics. In columns 1-4, we control for each of the four measures individually. The point estimates remain positive and significant across each specification. In column 5 , we control for all four controls simultaneously. Column 6 allows for the possibility of non-linear effects by also controlling for the square of each variable, while column 7 allows for interaction effects by also including all pairwise interactions of the controls. In each of the specifications, the points estimates remain robust, with magnitudes that are positive, significant and very similar in magnitude to the baseline estimate of 25.9.

We also check the robustness of the IV estimates to controlling for the additional covariates from Table 3. The results, which are reported in Table 7, show that the IV estimates, like the OLS estimates, remain robust to these additional controls. ${ }^{4^{\circ}}$

\footnotetext{
$4^{\circ}$ The results are similarly robust for the other outcome variables as well.
} 
Table 6: Robustness of IV estimates to additional geographic controls.

\begin{tabular}{|c|c|c|c|c|c|c|c|}
\hline & \multicolumn{7}{|c|}{ Dependent variable: FLFP } \\
\hline & $(1)$ & $(2)$ & (3) & $(4)$ & (5) & $(6)$ & (7) \\
\hline Historical plough use & $\begin{array}{c}-33.573 * * * \\
(11.777)\end{array}$ & $\begin{array}{c}-25.539 * * \\
(10.371)\end{array}$ & $\begin{array}{c}-27.842 * * * \\
(8.841)\end{array}$ & $\begin{array}{c}-18.427^{* *} \\
(9.068)\end{array}$ & $\begin{array}{c}-25.089 * * * \\
(9.300)\end{array}$ & $\begin{array}{c}-26.076 * * \\
(12.533)\end{array}$ & $\begin{array}{c}-26.245^{* *} \\
(10.696)\end{array}$ \\
\hline Terrain slope & yes & & & & yes & yes & yes \\
\hline Soil depth & & yes & & & yes & yes & yes \\
\hline Average temperature & & & yes & & yes & yes & yes \\
\hline Average precipitation & & & & yes & yes & yes & yes \\
\hline Quadratic terms & & & & & & yes & \\
\hline Linear interactions & & & & & & & yes \\
\hline Baseline controls & yes & yes & yes & yes & yes & yes & yes \\
\hline Observations & 157 & 154 & 157 & 157 & 157 & 157 & 157 \\
\hline R-squared & 0.29 & 0.38 & 0.38 & 0.38 & 0.44 & 0.44 & 0.44 \\
\hline
\end{tabular}

Table 7: Robustness of IV estimates to alternative controls.

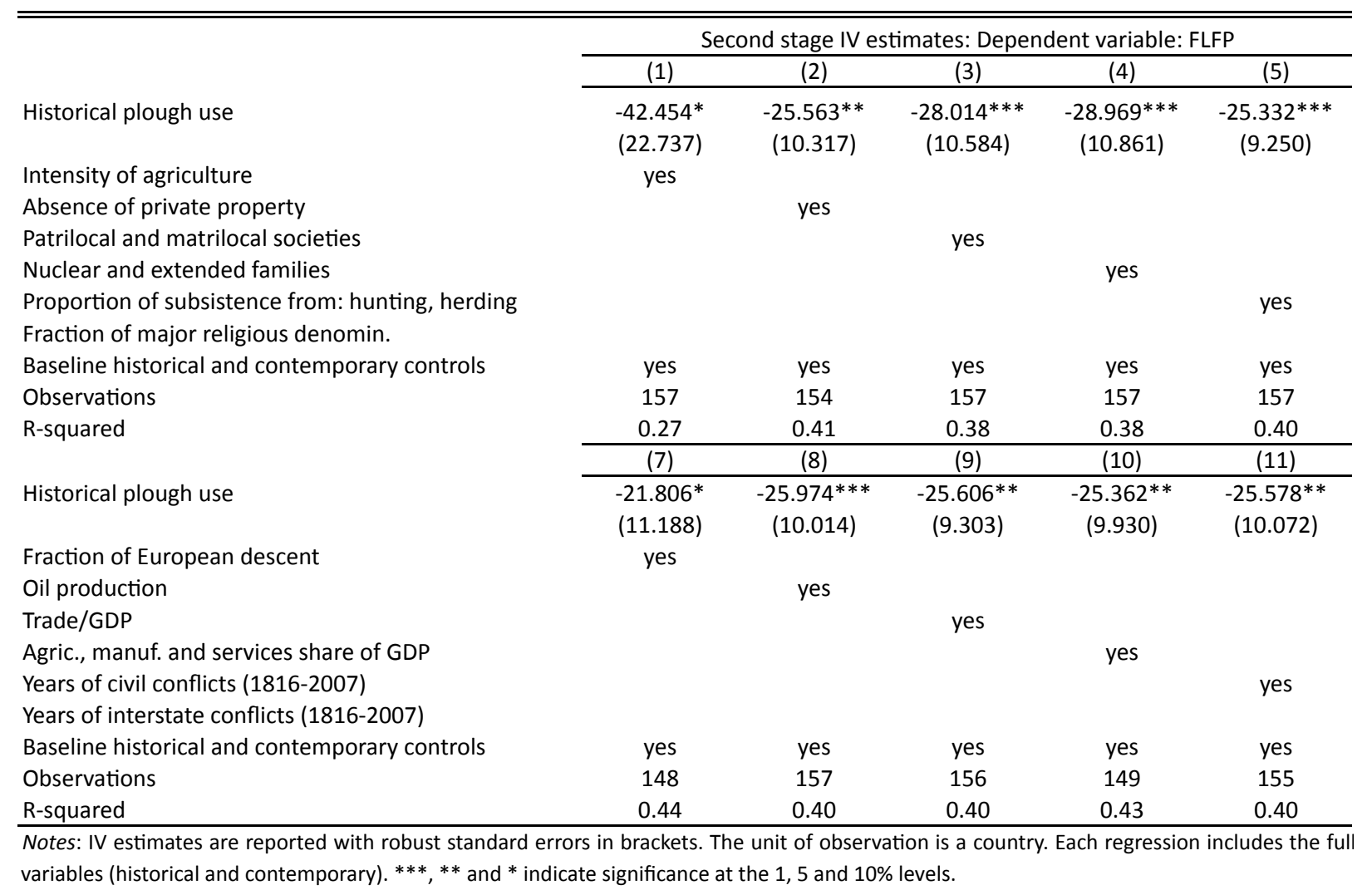


Table 8: Individual-level IV estimates.

\begin{tabular}{|c|c|c|c|c|}
\hline & \multicolumn{4}{|c|}{ Panel A. Second stage. Dependent variable: } \\
\hline & FLFP & $\begin{array}{c}\text { When jobs are } \\
\text { scarce }\end{array}$ & $\begin{array}{c}\text { Men better } \\
\text { political leaders }\end{array}$ & $\begin{array}{c}\text { Average effect size } \\
\text { (AES) }\end{array}$ \\
\hline & $(1)$ & $(2)$ & (3) & $(4)$ \\
\hline \multirow[t]{2}{*}{ Historical plough use } & $-0.585^{* *}$ & $0.576 * *$ & $1.383^{* * *}$ & $1.328 * * *$ \\
\hline & $(0.242)$ & $(0.229)$ & $(0.362)$ & $(0.386)$ \\
\hline Historical plough use (LIML) & -0.611 & 0.576 & 1.418 & \\
\hline $\mathrm{p}$-value & 0.00 & 0.00 & 0.00 & \\
\hline CLR intervals & {$[-0.700,-0.524]$} & {$[0.501,0.652]$} & {$[1.308,1.531]$} & \\
\hline Individual controls & yes & yes & yes & yes \\
\hline Contemporary country controls & yes & yes & yes & yes \\
\hline Historical district controls & yes & yes & yes & yes \\
\hline Continent FE & yes & yes & yes & yes \\
\hline Observations & 36,370 & 67,347 & 55,454 & 61,400 \\
\hline \multirow[t]{2}{*}{ R-squared } & 0.15 & 0.17 & 0.11 & \\
\hline & \multicolumn{4}{|c|}{ Panel B. First stage. Dependent variable: Historical plough use } \\
\hline \multirow[t]{2}{*}{ Plough-positive environment } & $0.273^{* * *}$ & $0.242 * * *$ & $0.338 * * *$ & \\
\hline & $(0.073)$ & $(0.079)$ & $(0.088)$ & \\
\hline \multirow[t]{2}{*}{ Plough-negative environment } & $-0.075^{*}$ & -0.041 & $-0.094^{*}$ & \\
\hline & $(0.044)$ & $(0.040)$ & $(0.055)$ & \\
\hline Equality of coefficients ( $p$-value) & 0.00 & 0.00 & 0.00 & \\
\hline F-stat (excluded instruments) & 7.13 & 4.74 & 7.29 & \\
\hline Hausman test ( $p$-value) & 0.00 & 0.03 & 0.00 & \\
\hline \multicolumn{5}{|c|}{$\begin{array}{l}\text { Notes: The table reports IV estimates, with standard errors clustered at the country level. The instruments are plough- } \\
\text { positive climate and plough-negative climate. Individual controls are age, age squared, education, gender (for gender } \\
\text { attitudes only), marital status, and income. Current country controls include In income, In income squared and a communism } \\
\text { indicator variable. Historical district controls include agricultural suitability, domesticated animals, tropical areas, political } \\
\text { hierarchies, and economic complexity. The AES reported in column } 4 \text { is for the two subjective belief measures from columns } \\
2 \text { and } 3 .{ }^{* * *},{ }^{* *} \text { and }{ }^{*} \text { indicate significance at the } 1,5 \text { and } 10 \% \text { levels. }\end{array}$} \\
\hline
\end{tabular}

\section{B. Individual-level estimates}

Table 8 reports IV estimates of equation (3), which examines variation across individuals in the WVS. Consistent with the individual-level OLS estimates, the IV estimates also identify persistent impacts of historical plough use. We estimate a negative effect of past plough use on the participation of women in the labor force, and a positive effect on the prevalence of attitudes of gender inequality. Like the country-level estimates, we find that the IV estimates are larger than the OLS estimates.

\section{Cultural transmission as a mechanism: Evidence from US immigrants}

We now turn to an examination of the causal mechanisms underlying our results. Although our focus is on the evolution and persistence of cultural norms, it is possible that part of the long-term 
effect of the plough may have arisen because it led to the development of institutions and markets which are less conducive to the participation of women in activities outside of the domestic sphere. Through this channel, the plough causes less female participation in market activities because it affects the costs and benefits of these activities, not because it affects individuals' beliefs about whether these are appropriate activities for women.

Our individual-level estimates, showing an impact of the plough on gender-role attitudes, provide evidence that the plough has impacted beliefs and values. However, these effects may have resulted from differences in external factors (e.g., institutions, policies, markets, etc), which in turn shape individual beliefs. To better isolate the causal impact of the plough on individual beliefs and values, we examine variation among second-generation immigrants - a group of individuals from diverse cultural backgrounds with different histories of ancestral plough use, but facing the same external environment, including markets, institutions and policies. Using data from the March Supplement of the Current Population Survey (CPS), we examine whether women with an ancestry of plough agriculture are less likely to be in the labor force today ${ }^{41}$ We identify the ancestry of women in the sample using their parents' country-of-birth, measured using either the mother's country of birth, the father's country of birth, or both parents' country of birth (after restricting the sample to those with parents that have the same country of birth). One benefit of the different definitions of ancestry is that it allows us to examine whether cultural transmission is stronger from the father to the daughter, the mother to the daughter, or when both occur together.

Our analysis examines two samples of women, one that includes all women aged 15 to 64 and another that only includes married women in the same age group. When we examine married women only, we are able to also examine the impact of traditional plough use working through the husband's lineage. We identify a tradition of plough use among the husband's ancestor using either his father's country of birth, his mother's country of birth, or both.

We estimate the impact of the plough on immigrant populations using the following equation:

$$
y_{i, s, c}=\alpha_{s}+\beta \text { Plough }_{c}+\mathbf{X}_{c}^{\mathrm{C}} \boldsymbol{\Gamma}+\mathbf{X}_{c}^{\mathrm{H}} \boldsymbol{\Pi}+\mathbf{X}_{i} \boldsymbol{\Phi}+\varepsilon_{i, s, c}
$$

where $i$ denotes a second-generation woman currently living in state $s$, whose country of origin

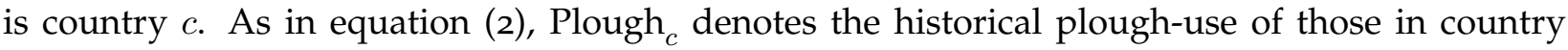

\footnotetext{
${ }^{41}$ Starting in 1994, the CPS asks individuals about their country of origin and their parents' country of origin. We use all the years available since 1994 .
} 
c. $\alpha_{s}$ denote state fixed effects. The dependent variable, $y_{i, s, c}$, is an indicator variable that equals one if individual $i$ is in the labor market. $\mathbf{X}_{c}^{\mathbf{C}}$ and $\mathbf{X}_{c}^{\mathbf{H}}$ denote the same vectors of covariates as in equation (2), which include current and historical ethnographic controls. $\mathbf{X}_{i}$ indicates a vector of individual level controls, which includes dummies for education, a quadratic for age, real personal income, marital status, fixed effects for whether the person lives in a metropolitan or rural area, and fixed effects for the year of the survey. When we use the sample of married women we also include controls for characteristics of the husband: a quadratic of the husband's age, the

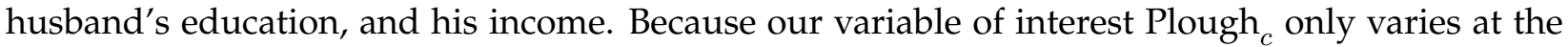
country of origin-level, we cluster all standard errors at this level.

The OLS estimates are reported in Table 9. Columns 1-3 report estimates using the full sample of women. Column 1 identifies the women's ancestry by her father's country of birth, while column 2 uses the mother's country of birth. In column 3, we restrict the sample to women whose parents were both born in the same country. For all three specifications, we estimate a negative relationship between a tradition of plough-use in the home country and the women's participation in the labor force. IV estimates of the same specifications, reported in columns 1-3 of Table 10, yield nearly identical results.

Columns 4-9 of Tables 9 and 10 report OLS and IV estimates using the sample of married women. Columns 4-6 reproduce the estimates of columns 1-3 for the sample of married women, when we identify ancestry using the wife's parents. We continue to find a negative impact of traditional plough use on female labor force participation, although we now find a smaller estimated impact when we identify ancestry using the father's country of birth. The impact is roughly $50 \%$ lower for both the OLS and IV estimates. This provides evidence that, at least for the subsample of married women, the transmission of values and beliefs (originating from the plough) is stronger from mothers to daughters than from fathers to daughters.

We next consider the possibility that a married woman's participation in the labor market may be influenced by her husband's beliefs and values, which were transmitted from his parents and their cultural background. Columns 7-9 of Tables 9 and 10, reproduce the estimates of columns 4-6 from the same tables, when we identify ancestry using the husband's parents rather than the wife's parents. The estimates provide evidence for an impact of a history of plough use among the husband's ancestors on the wife's participation in the labor market. Differentiating between the husband's parent's and their ancestry, we find a weaker estimate when we use the husband's 


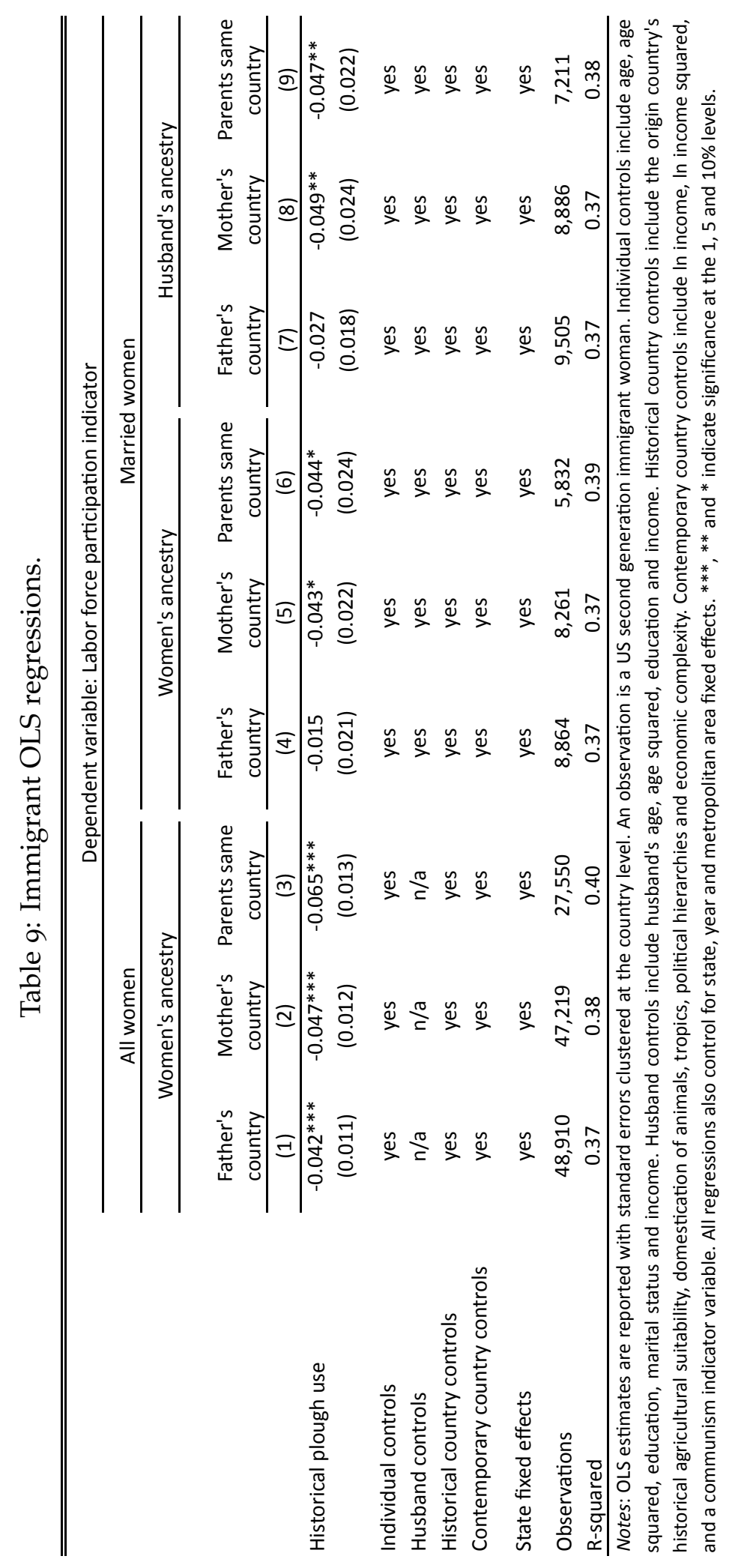




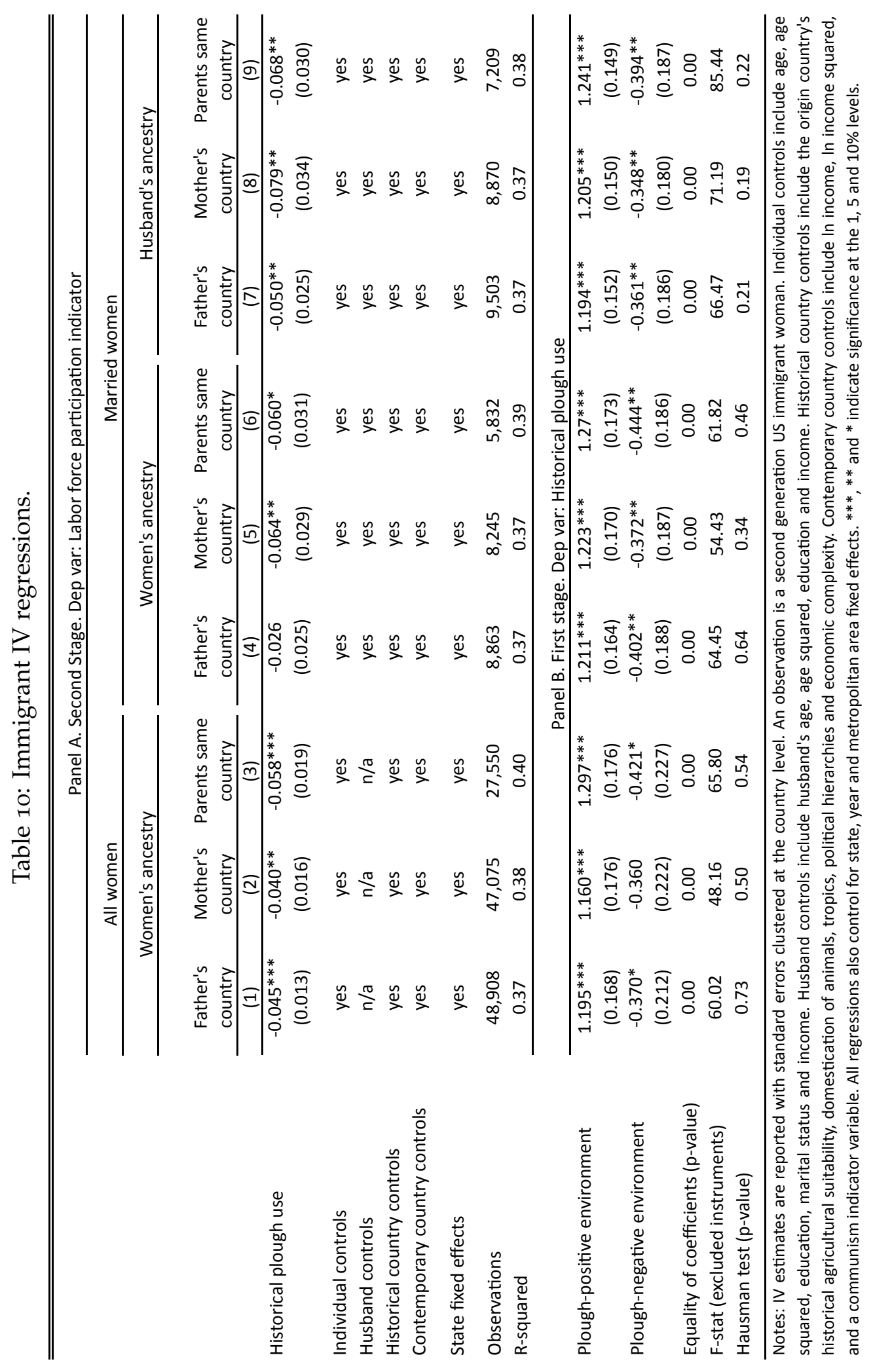


father's country of birth than the husband's mother's country of birth. Like the case for the women's parents, these estimates identify weaker transmission from the father than from the mother. In other words, the transmission of beliefs about gender appears stronger from mothers (than fathers), whether it is from the wife's mother to the wife or the husband's mother to the husband.

It is also interesting that, in every specification, the estimated impact of the plough transmitted through the husband's parents is stronger than the impact of the plough transmitted through the wife's parents (i.e., compare columns $4-6$ with 7-8). This suggests that the beliefs of the husband are at least as important, if not more important, than the beliefs of the wife in determining whether she enters the labor force. This result is consistent with the previous findings of Fernandez and Fogli (2009).

Comparing the magnitude of the immigrant estimates with the country-level estimates allows us to glean some evidence of the relative importance of cultural transmission, relative to other channels, in explaining the relationship between historical plough use and female labor force participation. The impact of the plough on US second-generation immigrant women is much smaller than the estimated impact from the country-level regressions. Consider the estimated impact on female labor force participation from a one-unit change in historical plough use (i.e., an increase zero to one). Using the country-level OLS estimates (column 1 of Table 2), this is associated with an increase in FLFP by 16 percentage points. The individual-level estimates (column 1 of Table 4) suggest impacts of a similar magnitude: 21 percentage points. However, the magnitudes based on the immigrant-level estimates are much smaller in magnitude, ranging from 4 to 6 percentage points (columns 1-9 of Table 9). Although one must interpret these findings with caution, the relative magnitudes suggest that internal norms (identified in the immigrant regressions) account for approximately a quarter to a third of the overall impact of the plough on gender roles.

\section{Conclusions}

Social anthropologists have long-considered the use of shifting hoe cultivation vs. plough cultivation as an important determinant of the evolution and persistence of traditional gender roles and norms. We formally test this hypothesis by combining ethnographic data on traditional plough 
use, measured at the ethnicity level, with contemporary data measuring gender attitudes and female participation outside of the domestic sphere.

Our findings provide evidence that current differences in gender attitudes and female behavior have indeed been shaped by historical differences in agricultural systems. Specifically, we have shown that individuals, ethnicities and countries whose ancestors used the plough have beliefs that exhibit greater gender inequality today and have less female participation in non-domestic activities, like market employment, entrepreneurship, and politics. In an effort to identify a channel of cultural persistence, we examined variation across second-generation female immigrants born and living in the US, but from different cultural backgrounds. We find that even among this group of individuals, who face the same labor market, institutions, and policies, a history of plough use is associated with less female labor force participation.

\section{References}

Albanesi, Stefania and Claudia Olivetti, "Gender Roles and Technological Progress," Working Paper 13179, NBER June 2007.

_ and _, "Home Production, Market Production and the Gender Wage Gap: Incentives and Expectations," Review of Economic Dynamics, 2009, 12, 80-107.

Alesina, Alberto and Nicola Fuchs-Schundeln, "Good-Bye Lenin (or Not?): The Effect of Communism on People's Preferences," American Economic Review, 2007, 97 (4), 1507-1528.

- and Paola Giuliano, "The Power of the Family," Journal of Economic Growth, June 2010, 15 (2), 93-125.

_ , Yann Algan, Pierre Cahuc, and Paola Giuliano, "Family Values and the Regulation of Labor," 2010. NBER Working Paper 15747.

Barry, H., M. Bacon, and I. Child, "A Cross-Cultural Survey of Some Sex Differences in Socialization," Journal of Abnormal and Social Psychology, 1957, 55, 327-332.

Baumann, Hermann, "The Division of Work According to Sex in African Hoe Culture," Africa: Journal fo the International African Institute, 1928, 1 (3), 289-319.

Becker, Sasha O., Katrin Boeckh, Christa Hainz, and Ludger Woessman, "The Empire is Dead! Long Live the Empire," 2010. Mimeo, University of Stirling.

Borck, Rainald, "Adieu Rabenmutter - The Effect of Culture on Fertility, Female Labor Supply, the Gender Wage Gap and Childcare," 2011. CESIFO Working Paper No. 3337.

Boserup, Ester, Woman's Role in Economic Development, London: George Allen and Unwin Ltd., 1970.

BP Oil, “Quantifying Energy," 2006. BP Statistical Review of World Energy, June 2006.

Braudel, Fernand, Mediterranean in the Ancient World, London: Allen Lane, 1998. 
Carranza, Eliana, "Soil Endowments, Production Technologies and Missing Women in India," 2010. Mimeo, Harvard University.

Clingingsmith, David, Asim Ijaz Khwaja, and Michael Kremer, "Estimating the Impact of the Hajj: Religion and Tolerance in Islam's Global Gathering," Quarterly Journal of Economics, 2009, 124 (3), 1133-1170.

Engels, Frederick, The Origin of the Family, Private Property and the State, Chicago: Charles H. Kerr \& Company Cooperative, 1902.

Fernandez, Raquel, "Women, Work and Culture," Journal of the European Economic Association, $2007,5(2-3), 305-332$.

- and Alessandra Fogli, "Culture: An Empirical Investigation of Beliefs, Work, and Fertility," American Economic Journal: Macroeconomics, 2009, 1 (1), 146-177.

Fischer, Gunther, Harrij van Nelthuizen, Mahendra Shah, and Freddy Nachtergaele, Global Agro-Ecological Assessment for Agriculture in the 21st Century: Methodology and Results, Rome: Food and Agriculture Organization of the United Nations, 2002.

Fortin, Nicole, "Gender Role Attitudes and the Labour Market Outcomes of Women Across OECD Countries," Oxford Review of Economic Policy, 2005, 21, 416-438.

_ , "Gender Role Attitudes and Women's Labor Market Participation: Opting-Out, AIDS, and the Persistent Appeal of Housewifery," 2009. Mimeo, University of British Columbia.

Foster, Andrew D. and Mark R. Rosenzweig, "Comparative Advantage, Information and the Allocation of Workers Tasks: Evidence from an Agricultural Labour Market," Review of Economic Studies, 1996, 63 (3), 347-374.

Goldin, Claudia, "The U Shaped Female Labor Force Function in Economic Development," in T. Paul Schultz, ed., Investment in Women Human Capital, Chicago: University of Chicago Press, 1995, pp. 61-90.

_ " "The Quiet Revolution that Transformed Women's Employment Education and Family," American Economic Review Papers and Proceedings, 2006, 96 (2), 1-23.

- and Kenneth Sokoloff, "The Relative Productivity Hypothesis of Industrialization: The American Case, 1820 to 1850," Quarterly Journal of Economics, 1984, 99 (3), 461-487.

Goody, Jack, Production and Reproduction, Cambridge, UK: Cambridge University Press, 1976.

Gordon, Raymond G., Ethnologue: Languages of the World, 15th Edition, SIL International, 2005.

Grosjean, Pauline, "The Determinants of Cultural Integration: A Gravity Approach," 2010. Mimeo, University of San Francisco.

_, "A History of Violence: Testing the "Culture of Honor" in the US South," 2010. Mimeo, University of San Francisco.

Guiso, Luigi, Paola Sapienza, and Luigi Zingales, "Long-Term Persistence," 2008. Mimeo.

_ , _, and _ , "Social Capital as Good Culture," Journal of the European Economic Association, 2008, $6(2-3), 295-320$.

Iversen, Torben and Francis Rosenbluth, Women, Work, and Politics: The Political Economy of Gender Inequality, New Haven: Yale University Press, 2010. 
Kling, Jeffrey, Jeffrey Liebman, Lawrence Katz, and Lisa Sanbonmatsu, "Moving to Opportunity and Tranquility: Neighborhood Effects on Adult Economic Self-Sufficiency and Health from a Randomized Housing Voucher Experiment," 2004. Mimeo, Harvard University.

Mazoyer, Marcel and Laurence Roudart, A History of World Agriculture: From the Neolithic Age to the Curren Crisis, New York: Monthly Review Press, 2006.

McCleary, Rachel M. and Robert J. Barro, "Religion and Economy," Journal of Economic Perspectives, 2006, 20 (2), 49-72.

Michalopoulos, Stelios, "The Origins of Ethnolinguistic Diversity: Theory and Evidence," 2008. Mimeo, Tufts University.

Murdock, George Peter and Caterina Provost, "Factors in the Division of Labor by Sex," Ethnology, 1973, 12 (4), 203-225.

_ and Douglas R. White, "Standard Cross-Cultural Sample," Ethnology, October 1969, 8 (4), 329-369.

Nunn, Nathan and Diego Puga, "Ruggedness: The Blessing of Bad Geography in Africa," Review of Economics and Statistics, 2011, p. forthcoming.

- and Leonard Wantchekon, "The Slave Trade and Origins of Mistrust in Africa," American Economic Review, 2011, p. forthcoming.

- and Nancy Qian, "The Potato's Contribution to Population and Urbanization: Evidence from an Historical Experiment," Quarterly Journal of Economics, 2011, p. forthcoming.

Pitt, Mark M., Mark R. Rosenzweig, and Nazmul Hassan, "Human Capital Investment and the Gender Division of Labor in a Brawn-Based Economy," 2010. Mimeo.

Pryor, Frederic, "The Invention of the Plow," Comparative Studies in Society and History, 1985, 27 (4), 727-743.

Putterman, Louis and David N. Weil, "Post-1500 Population Flows and the Long-Run Determinants of Economic Growth and Inequality," Quarterly Journal of Economics, November 2010, 125 (4), 1627-1682.

Recklein, John C., A Profile of Economic Plants, Oxford: Transaction Books, 1987.

Ross, Michael L., "Oil, Islam and Women," American Political Science Review, 2008, 102 (1), 107123.

Tabellini, Guido, "The Scope of Cooperation: Values and Incentives," Quarterly Journal of Economics, 2008, 123 (3), 905-950.

Weidmann, Nils B., Jan Ketil Rod, and Lars-Erik Cederman, "Representing Ethnic Groups in Space: A New Dataset," Journal of Peace Research, 2010, 47 (4), 491-499.

Whyte, Martin King, The Status of Women in Pre-Industrial Societies, Princeton, N.J.: Princetone University Press, 1978. 